$$
\text { WHOI -79-81 }
$$

\title{
A STUDY OF CTD CABLES AND LOWERING SYSTEMS
}

\author{
by
}

H.0. Berteaux, R.G. Walden,

D.A. Moller, Y.C. Agrawal

\section{WOODS HOLE OCEANOGRAPHIC INSTITUTION Woods Hole, Massachusetts 02543}

\author{
December 1979
}

TECHNICAL REPORT

Prepared for the Office of Naval Research under Contract N00014-76-C-0197; NR 083-400.

Reproduction in whole or in part is permitted for any purpose of the United States Government. This report should be cited as: Woods Hole Oceanographic Institution Technical Report WHOI-79-81.

Approved for public release; distribution unjimited. Approved for Distribution: Thaluin Q. Fenerfelef Department of Ocean Engineering 
Acknowledgements

Abstract

1.0 Causes and Modes of Failure

1.1 Background

1.2 Failure Factors

1.3 Summary

2.0 Improving the Reliability of Present E/M CTD Cables and Lowering Systems and Procedures

2.1 Quality Control and Acceptance Testing of New Cables 7

2.2 Installing New Cables on Board Ships

2.2.1 Winding New Cable on the Winch Drum

2.2.2 Streaming and Rewinding the New Cable at Sea

2.2.3 Sheaves

2.3 E/M Cable Maintenance Program

2.3.1 Documentation

2.3.2 Inspection and Tests

2.3.3 Preventive Maintenance-Lubrication Long Term Storage

2.3.4 Reversing

2.3.5 Cable Reconditioning

2.3.6 Cable Retirement

Winch Maintenance and Winch Monitoring Instrumentation 16

2.5 Operationa1 Limits

2.5.1 Depth Limits

2.5.2 Speed Limits

3.1 Review of Possible E/M Cable Candidates 22

3.1.1 Special Steel Armor Cables 23

3.1.2 Synthetic Fiber Cables $\quad 23$

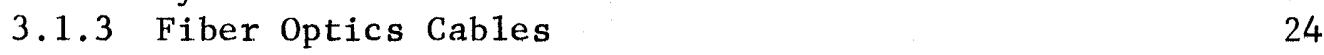

3.2 Redesign of CTD Instrument Package 36

$\begin{array}{lll}4.0 & \text { Conclusions/Recommendations } & 37\end{array}$

5.0 Appendices $\quad 40$

1. C'DD Cable Fatigue Test Report

2. Evidence of Probarle Cause of Kinking and Conductor

Failure in CID Lowering Cables (R/V KNORR Cruise 非73)

3. E/M Cable Specifications

4. E/M Cable Life History Documentation

5. Lubricant Data Sheet

6. Winch Documentation (CTD(Acoustic)Winch Maintenance Log)

7. Computation of Peak Tension in CTD Cables at the Head Sheave of a Ship Undergoing Both Heave and Ro11

8. Measurement of CTD Package Terminal Velocity

9. Spooling E/M Cable on Smoothed Surface Drums 


\section{Acknowledgements}

The authors want to express their gratitude to Messrs. A. Berian and W. Garne, Engineers with the Rochester Corporation, for testing and evaluating samples of various CTD cables and for providing technical data essential to this report.

Open discussions held with Mr. R. Reiniger of the Bedford Institute of Oceanography (Canada) on CTD cable experience and CTD packages performance measurements were also very constructive.

The excellent work done by Peter Clay, engineer of the buoy group, who developed an instrument and a method to measure the terminal velocity of free-falling packages and by Michael Cook, graduate student in the Ocean Engineering MIT/WHOI Joint Education Program, who wrote the computer program to predict tension levels of the cable, deserves a special mention.

C. Collins, also from the buoy group, gathered most of the CTD lowering systems background information.

The assistance of Mrs. C. Muzzey and of the Graphic Arts Department in typing and preparing this report is also gratefully acknowledged.

The work reported hereafter received support from the Office of Naval Research, Contract No. N00014-76-C-0197; NR 083-400, Code 480/485. 


\section{ABSTRACT}

This study first reviews both the electrical and mechanical modes and causes of failure of electromechanical (E/M) cables used to lower deep sea sensors, such as CTD instruments, from oceanographic ships.

It then outlines measures or steps that could be taken to correct some of the deficiencies observed and improve the systems presently used. These measures include quality control, tests, operational limits, improved handling and maintenance, improved machinery.

The study then surveys alternative cables for lowering the sensors and convey the information from the sensors back to the ship. These alternatives include strength members other than steel (Kevlar) and signal carriers other than conventional copper conductors (fiber optics).

The final section - Conclusions - surmarizes the recommendations, based on this study, for improving the reliability of present and future CTD lowering systems. 


\subsection{Causes and Modes of Failure}

\subsection{Background}

One way to obtain measurements of oceanographic parameters at great depths is to lower sensing instrument packages with electromechanical cable. Of necessity these cables are kept to sma11, workable sizes but because of the long lengths deployed the weight often results in very high tension levels. Vessel motion due to wave action introduces additional cyclic loads which can and often cause cable deterioration due to fatigue. Salt water exposure and resulting accelerated corrosion of the cable armor wires further compound the problem.

Failure of the cable, which could be defined as the loss of electrical signal between the lowered sensor package and the recording unit on board ship, can result from one of the following reasons:

- Complete rupture of the cable, resulting in total instrument loss.

- Rupture in one or several points of the copper conductor(s), resulting in open circuit.

- Puncture in one or several points of the insulation, resulting in short circuit.

- Poor performance of the winch slip rings at the shipboard end. These failure causes, in turn, may stem from the winch machinery, deployment and recovery methods, cable storage and handling procedures, and the environment in which the system is used.

As part of this study a survey was made of existing CTD lowering systems and related problems. This survey included questionnaires sent to users outside the Woods Hole Oceanographic Institution, interviews, and wherever possible, visits of shipboard CTD installations. Recommendations were also solicited from manufacturers. The results from this survey indicate that the types and frequency of occurrence of common problems are shared by a sufficient number of users to make this study worthwhile. 
Problems often mentioned in the survey included cable kinking, birdcaging of the armor wires, cable crushing, insulation rupture, broken conductors, poor level winding and corrosion. Perhaps the most striking information of the survey was that at least nine CTD instruments had been lost a sea by different members of the Oceanographic community within the last few years.

It is hoped that reviewing the failure causes in some detail, and that suggesting appropriate recommendations will help improve the life and the performance of present CTD systems.

\subsection{Failure Factors}

\section{High Tensile Loads}

While hanging free from the ship, the tension in the cable is the sum of the static load due to cable and instrument immersed weight and the dynamic load due to cable and attached instrument inertia and hydrodynamic resistance. The static load increases linearly with the length of cable paid out. The dynamic load, on the other hand depends on the physical characteristics of the cable and instrument package, such as elasticity, mass, shape, volume, etc., and of course on the sea state. When these characteristics and the sea state are known, a reasonable prediction of the total

tensile load can be made by computer model. These anticipated loads can then be compared with the actual yield strength of the cable, and load limits can be set for safe use of this particular cable.

\section{Fatigue}

Repeated bending over sheaves and drums, cyclic longitudinal

tension due to wave action and cable spin induce cyclic stresses resulting in fatigue deterioration of the armor wires and of the conductors.

It is a well known fact that the number of fatigue cycles to total rope failure dramatically decreases as the tension in the rope increases. In CTD lowering applications, because of the long lengths of $\mathrm{E} / \mathrm{M}$ cable required, 
the tension can reach a very large fraction of the cable strength. Under these conditions, only a few hundred cycles of repeated stresses can severly damage the cable. This has been evidenced by laboratory tests performed on samples of $\mathrm{E} / \mathrm{M}$ cables loaded at various cable tensions and cycled back and forth over a typical three wheel tension measuring device. (See Appendix 1, also Reference 1).

Fatigue deterioration of the outer armor can be relatively easily detected by looking for wire wear surfaces, broken outer wires, fish hooks, etc. The detection of fatigue effects on the inner armor and on the conductors is not so easy. It requires taking samples from the cable, opening them up, and performing a comprehensive examination of the inner wires, the insulation, and the conductors.

\section{Corrosion}

Corrosion is one of the most obvious causes of deterioration. It is easily detected, but its effects are not always well recognized.

Loss of metalic cross section and resulting reduction of strength is the best known and in this case the least important effect of corrosion. In running cable applications, loss of flexibility and abrasive action of corrosion products should be of equal concern.

In a dry rusty cable, wires cannot easily readjust their helical patterns as they pass over sheaves or as the tension varies with time. This results in fretting, necking, and uneven distribution of the tensile load. In addition, particles of rust inside the cable act as an abrasive compound. The combined result is, of course, accelerated wear. It should be noted that this wear is internal, and thus difficult to observe and detect.

Often tensile tests performed on samples of a rusty cable will show that the cable has retained most of its rated breaking strength, and the cable is pronounced fit for further use, whereas in many cases it would be advisable to retire it. 


\section{Mishandling}

Under mishandling or abuse are these causes of a less general nature as the ones previously mentioned. They may be accidental, one of a kind. More than often, their effects are catastrophical. Examples coming to mind are the following:

Kinks. Kinks start as loops of cable wound on themselves and when the loops are pulled tight armor wires and conductors are permanently bent thus severely damaging the cable at the kinks. The damaged armor will no longer sustain tensions as small as $25 \%$ or less of the rated breaking strength. Shorts or open circuits are likely to occur at the point of kink.

For loops to develop in a tensioned cable two condition must prevail. The cable must turn on itself, thus storing torsional energy, and the tension must be released. Most cables, with the exception of those properly torque balanced, will turn when free ended, as the case is in CTD lowering applications. All cables will turn if forced to turn by the payload's own spin.

The cable can become slack in a number of ways. During lowering, if the payout rate is such that the speed of the cable exceeds the terminal velocity of the payload (the velocity of the payload free fa11), then the cable will hang below the instrument package in some sort of a slack loop, probably full of kinks.

When on station, that is with the winch secured, ship roll will result in cable up and down motion. If the ensuing rate of fall of the cable is larger than the instantaneous rate of fall of the payload, the cable will again be slack. That this situation can prevail has been indeed evidenced by comparing actual measurements of CTD 
instrument packages terminal velocity with recorded cable payout rates as well as computed vertical speed of the head sheave due to ship heave and roll motion (see Appendix 2).

Finally and obviously, if the payload is lying on the sea floor, the lower end of the cable will be slack.

Shock Loads. Abrupt loading of the cable can be produced by the combined action of ship roll, heave, and pitch. For example, large tension levels can be suddenly attained when the cable is forced to accelerate upwards due to ship motion, while the payload is at rest or perhaps stil1 sinking.

Cross Winding. Cross winding is a major cause of $\mathrm{E} / \mathrm{M}$ cable electrical failure. Cross winding occurs when a cable loop is allowed to straddle or pass over a loop already on the drum. The tension in the cable creates large pressure levels on the drum and on the layers of cable already on it. As more cable is reeled in, the pressure eventually builds up to the point where the cable armor, at the point of cross over, yields and crushes the cable insulation and the conductors (see Figure 1). Cross winding is the consequence of poor level winding.

Jump Sheave. Unless completely contained in the sheave groove, cables can and do jump over the sheave checkplates. The cable is then bent over a sharp radius, and the armor wires can be permanently damaged.

\subsection{Summary}

A summary of $\mathrm{E} / \mathrm{M}$ cable failure modes and possible causes has been compiled by A. Berian (1975) (Reference 2). This instructive table is hereby reproduced for the reader's benefit. 


\section{the ROCIFESTER}

CULPEPER. VIRGINIA 22701

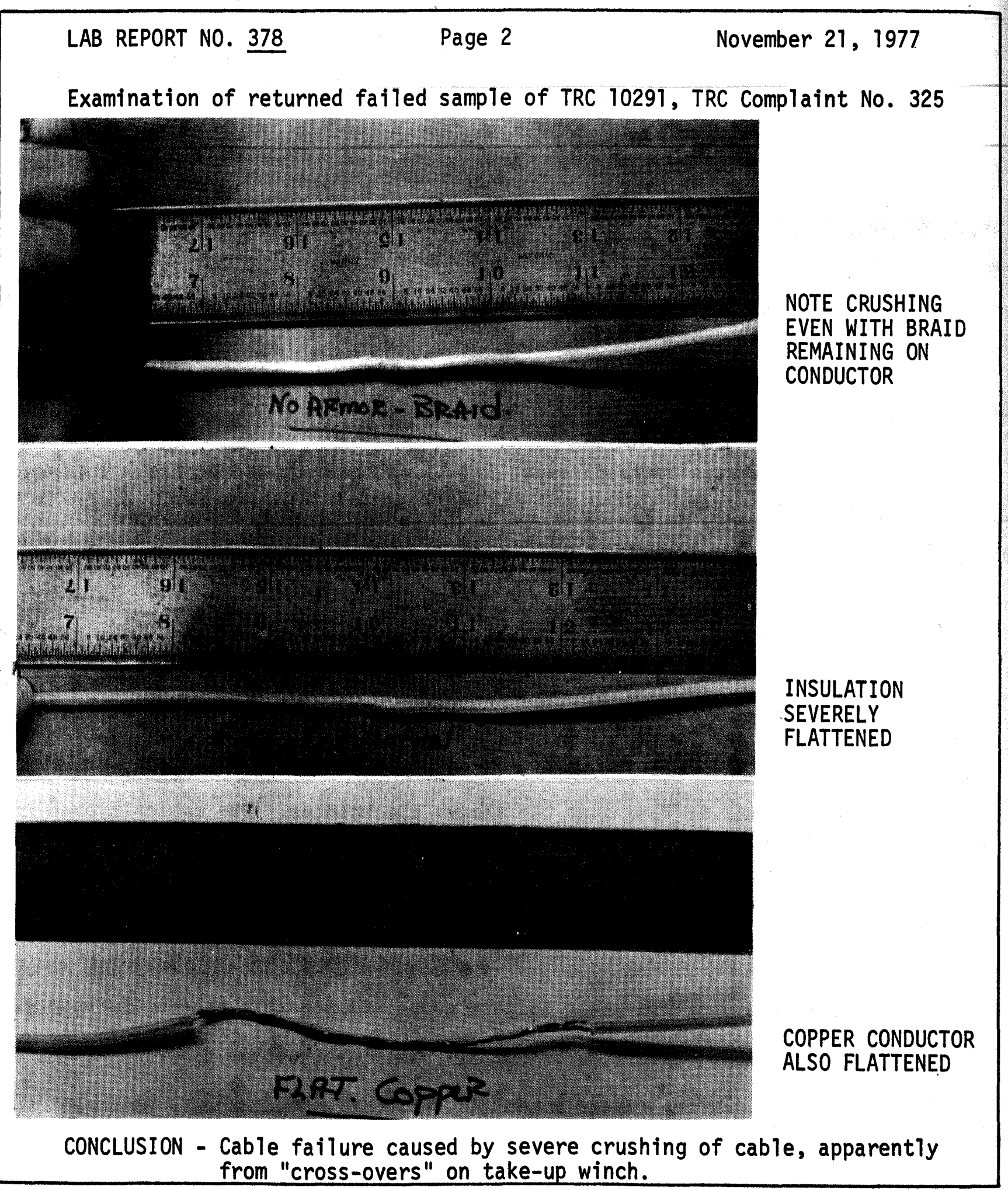

Figure 1. E/M Cable Crushed Due to Poor Level Winding 
Common Failure Modes for Contrahelically Armored Electrical Wirelines*

\section{Effect}

1. Local distortion of armor wires by crushing

2. Kinking of the cable

3. Birdcaging the armor

4. Yielding of some of the armor wires causing them to be higher than the remaining armor.

5. Rapid wear of the outer surface of the outer armor.

6. Rapid wear of surfaces between armor layers

7. Conductor shorted to armor or to each other.

8. Open circuit conductors.

\section{Causes}

1.a. Jumping a sheave

1.b. Crushing at cross-over points on a drum mostly due to sustained tension over $50 \%$ of breaking strength.

1.c. Physical damage by equipment runover, forks of a forklift truck, etc.

1.d. Loose armor.

2.a. Sudden relaxation of high tension forces.

2.b. Pulling directly on a cable loop without allowing cable rotation to elminate the loop.

3.a. Sudden relaxation of high tension forces.

3.b. Cable with loose outer armor operating in a tight pack-off.

4.2. Improper high tension loads causing yielding of the armor wires.

5.a. Smaller than recommended sheave grooves.

5.b. Improperly aligned sheaves.

5.c. Dragging on stationary surfaces.

5.d. Cable oversized due to foreign material solidifying between armors.

6.a. Poor lubrication.

6.b. Presence of abrasives.

6.c. Corrosion such as from salt water or hydrogen sulfide.

6.d. Sheave diameter too sma11.

7.a. High compression forces of the armor onto the insulation causes cold flow to the point of short circuit.

7.b. Softening of the insulation because of exceeding the rated temperature.

7.c. Chemical attack of the insulation.

8.a. Conductor overstressed because of overtensioning the cable.

8.b. Use of the cable over drums or sheaves having an improperly small diameter. 


\subsection{Improving the Reliability of Present E/M CTD Cables and Lowering}

\section{Systems and Procedures}

Recommended measures, some already implemented, which will improve the reliability of commonly used $\mathrm{E} / \mathrm{M}$ cables and of the existing lowering systems and handling procedures include the following.

\subsection{Quality Control and Acceptance Testing of New Cables}

The first step to insure good cable performance is to write a detailed cable specification at the time of purchase. This specification should not only outline the electrical and mechanical characteristics required for a particular application but it should also describe the acceptance testing procedure and certification.

Close consultation between user, purchaser, and the manufacturers sales and engineering departments is necessary to write sensible specifications. The in-house responsibility for receiving the finished product should be clearly assigned.

An example of good $E / M$ cable specification is shown in Appendix 3 .

New cables, when received, should be checked for good performance and compliance with specifications. The amount of testing will probably depend on past performance history.

In-house quality control tests to be routinely performed on newly received CTD cables include:

- Breaking strength; by pulling two or three sample lengths to destruction. The samples should be terminated at both ends with epoxy-filled sockets. Tests should be performed with both ends fixed and also with one end fixed and the other free to rotate.

- Size; by measuring the OD of the cable preferably in several places Note: the OD (Outside Diameter) of a CTD cable is usually taken as the mean of two measurements made at right angles from each other. Alternatively a three point micrometer can be used. 
- Continuity; by measuring the resistance of the conductor(s) between the two cable ends. An infinite resistance value would indicate a break in the conductor (open circuit).

- Insulation resistance; by measuring the resistance between the conductor(s) and the armor. A low or zero value would indicate a break in the insulation (short circuit). This test should be done at both ends of the cable, and preferably with the cable reel immersed in seawater, and at some prescribed DC voltage. An instrument - such as a Tektronix TDR (time domain reflectometer) should be acquired to measure CTD cable characteristics and pinpoint the type and location of cable faults.

The results of these tests should be part of the cable history record. (See E/M cable documentation, Section 2.3.1).

\subsection{Installing New Cables On Board Ships}

After reception the new $\mathrm{E} / \mathrm{M}$ cable must be removed from its shipping reel and wound onto the drum of the winch. Properly insta11ing long lengths of $\mathrm{E} / \mathrm{M}$ cables on winch drums is a difficult, lengthy, and critical operation. Detailed procedures to install new cables on winch drums have been described by cable and cable handling equipment manufacturers. Rather than condense these procedures, this section will point out the needs for good spooling and warn against potential problems.

\subsubsection{Winding New Cable on the Winch Drum}

Smooth, trcuble-free winding of highly tensioned cables on winches equipped with only one drum can be achieved if the oncoming cable is led and placed into an helical groove of proper pitch, size and strength. Starting at the drum face, this groove can be provided in one of two ways: either the groove, is machined in the drum face (grooved drum) or it is determined by the helical pattern of the first layer wrapped on a smooth drum 
(plain drum). The distance between the flanges and the diameter of the cable will determine the pitch and size of the helical groove needed for a particular grooved drum, or, in the case of a smooth face drum, the number of wraps in the first layer. With the first layer fitted, the space between adjacent cable wraps now constitutes the "groove" for the second layer. When installed, the second layer will repeat the pattern of the first and will in turn form the "groove" for the third layer. This repeated process, which hopefully can take place at high speeds, obviously will not work if the first layer is not properly installed.

It should be noted that grooved drums will not accept cables of diameters different from the one (and only one) they were designed for. It should also be clear that after satisfactory installation the first layer should never be touched, unless the whole cable is to be removed from the drum.

When spooled on the drum the new cable should always be wound under tension. This is required to insure that the cable resists compressive distortion and retains a circular cross section thus preserving the uniformity of the helical pattern from one layer to the next. Furthermore, a cable which has been spooled under tension will not, when in use, cut deep in the underlaying layers as the case would be if these layers were loose. Proper groove geometry and strength are necessary but not sufficient to insure good level winding. In addition, and as previously mentioned, the oncoming cable must be properly led. This is achieved either by making the cable fleet angle sma11 or by positively controlling the cable travel from one flange to the other. The fleet angle, that is the angle that the cable makes with a line drawn from the closest sheave to a point midway between the flanges, should not exceed one and one quarter degrees. This means that the closest sheave or block should be placed 25 drum-widths away from the winch. 
Thus if the drum is three feet wide, the first sheave should be at least 75 feet away from the winch, a condition not easily satisfied on board ships except when at the dockside.

Positive control of cable travel is achieved with the help of a level winding sheave mounted on the winch close to and ahead of the drum. The sheave, driven by a diamond thread gear, travels back and forth from one flange to the other guiding the cable as it is spooled in. To achieve good level winding the throw of the thread must exactly match the distance between the flanges, and the timing gear must be carefully adjusted so that the level winding sheave advances exactly one cable diameter per drum revolution. If the cable is not properly guided, gaps will appear between adjacent wraps (fast sheave) or wraps will have a tendency to "bunch" or climb on each other (slow sheave). These defects will cause sinking and/or binding of subsequent layers. They must therefore be corrected as soon as detected. Poor level winding is a major cause of $\mathrm{E} / \mathrm{M}$ cable abuse.

To install a new cable at the Woods Hole Oceanographic Institution the procedure starts by feeding the inboard end of the cable into a hole in the flange. A generous "pig tail" (four feet or so) is thus looped and clamped on the outside of the flange. The winch is then started and the cable, under tension ranging from $25 \%$ to $35 \%$ of its breaking strength, is carefully installed in the grooves of the grooved drum. When this is completed, the second and subsequent layers are carefully wrapped, tapping the cable in place as necessary, and adjusting the speed of advance of the level winding sheave for perfect level winding. As the cable is wound the tension is progressively reduced to a few hundred pounds at the end of the winding operation.

Detailed guide lines for properly installing $E / M$ cables on smooth drums can be found in Reference Number 2 and in Appendix No. 9. Groove 
design specifications and spooling procedures for grooved drums can be obtained from the Le Bus Corporation.

\subsubsection{Streaming and Rewinding the New Cable at Sea}

On occasions, and because of lack of proper tensioning equipment it will be impossible to load the new cable on board ship under high tension. A technique to provide the high tension levels required for safe and trouble-free use of the cable consists in streaming its entire length, except of course the first layer on the drum, astern of the ship underway. The combination of cable weight and drag will then provide a reasonable degree of winding tension. Obviously this must be done at a speed and over a bottom depth which insure that the cable lower end is not dragging on the ocean floor. Skippers and Chief Scientists who intend to use this technique should be provided with curves, specifically computed for the particular cable, which will give the maximum cable length before touching bottom as a function of ship speed and bottom depth.

When rewinding the cable on board ship the precautions previously mentioned to insure perfect level winding of the entire cable length should natura11y be followed.

This technique has the following disadvantages:

- It consumes costly ship time (6 hours or more),

- It requires the ship to sail to reasonably deep waters,

- The entire length of the new cable is immersed in salt water and stored wet on the drum. To help prevent corrosion of the rarely used, rarely seen bottom layers, the cable should be rinsed with fresh water as it comes in.

\subsubsection{Sheaves}

Sheaves installed along the cable path from the winch to (and including) the head block should be of the proper pitch diameter and groove size. By industry standards the pitch diameter should be 400 
times the size of the largest wire in the armor. Sheave groove diameter should be about $4 \%$ larger than the $\mathrm{E} / \mathrm{M}$ cable diameter. If the groove is too small the armor will distort in the groove causing a great deal of friction and rapid wear of armor wires. If the groove is too large, by selection or wear, the cable becomes elliptical. The result is distortion, flattening, and accelerated wear of the armor wires.

\subsection{E/M Cable Maintenance Program}

\subsubsection{Documentation}

A cable history record is essential to any cable maintenance program. Each cable should have its own log, started at the time of cable reception and ended at the time of cable retirement. This log, kept by shore-based personnel (marine department or scientific group), contains the basic facts concerning the cable characteristics, and life history.

Information on cable use and maintenance while at sea is provided by shipboard cable log sheets which should be completed at the end of each cruise and returned to the personnel in charge of the main log. These log sheets should provide factual information such as a short description of the lowering purpose, length of cable paid out and speed, comments on weather, special events, and maintenance performed at sea. Their format should make them easy to complete. A recommended shipboard log sheet form is shown in Appendix 4. Such $10 \mathrm{~g}$ sheets should be supplied by the marine department to the ship's first mate prior to each cruise.

Information contained in the main $10 \mathrm{~g}$ should include a cable description, a record of the acceptance tests and all significant data pertinent to cable usage, maintenance, and final disposition. A recommended format for the cable main $\log$ is also shown in Appendix 4. 


\subsubsection{Inspection and Tests}

A very convenient and appropriate time for inspecting a CTD cable is while paying out. The type and location (meters out) of defects observed should be noted and logged (page 2 of Shipboard E/M Cable Log, Appendix 4) to permit closer inspection on subsequent runs or ashore. Defects to be reported include: kinks, flattening of cable, birdcage armor wires (fish hooks, unlaid single wire), and extensive amount of corrosion. The electrical resistance of conductors and insulation should also be checked periodically.

A more detailed inspection of the entire cable length should be made when the cable is removed from a ship and stored on a storage drum. A meter wheel should be used to again locate the defects as well as to measure the remaining length of cable stored. This information should be entered in the $E / M$ cable main $\log$ (Items 3.2 and 4.0, and Appendix 4). Samples of the cable should be cut at both ends and pull-tested to destruction. Test results should also be recorded in the cable main log.

\subsubsection{Preventive Maintenance-Lubrication - Long Term Storage}

Preventive maintenance is done either at sea when the cable is used on board ship or ashore while in long term storage. Preventive maintenance essentially consists in rinsing off salt water and applying a lubricant to the cable armor. Lubrication reduces internal frictional wear and inhibits corrosion of armor wires thus increasing the useful life of $\mathrm{E} / \mathrm{M}$ cables by as much as two to four times. Applying the lubricant should be made as easy as possible, either by automatic feed or simply by brushing or spraying with a spray gun. A lubricant which has been successfully used by the marine community to relubricate wire ropes and cables is described in Appendix 5. In applications where lubricants could contaminate scientific samples, a leader of inert material could be used. 
Maintenance at Sea. The E/M cable should be hosed down with fresh water after the final deployment on each cruise and, if possible, blown dry with compressed air before winding it on the winch drum. Furthermore, if the cable is not to be reused for a long time and/or has not been relubricated since a given period (say three months) then a lubricant should be applied to each fleet (layer) of cable wound on the winch drum.

Long Term Storage. When the $E / M$ cable is removed from shipboard to be stored ashore for long periods of time, the cable should be rinsed, blown dry, and inspected for defects as it is reeled on the storage drum. A coat of lubricant should be applied at the same time. The cable. should be run through a meter wheel and the exact length stored recorded. The storage reet should be tagged or painted for proper identification. The cable should be stored inside a warehouse, not in the open. The storage operation should be entered in the cable main log.

\section{3 .4 Reversing}

The practice of reversing an $E / M$ cable should not be encouraged. In general more casts are made at moderate depths than at very large ones. As a result the outer layers are subjected to more use, and therefore have more wear and corrosion than the layers close to the drum. If the cable is reversed end-for-end, then it is the worn section of the cable which will eventually be subjected to the maximum tension levels, and cable failure may occur.

\subsubsection{Cable Reconditioning}

When inspection shows that abrasive wear over a certain cable length is more than $5 \%$ of the cable initial diameter, it is common practice to discard the worn section.

If the other signs of aging are corrosion and/or loose armor, the rest of the cable can be restored by the manufacturer to a condition 
close to the original by reconditioning procedures which include external wire brushing, offset rolling which cleans the armor layers of dirt and corrosion products, outer armor tightening and finally industrial lubrication, Cost of cable reconditioning is economical, being approximately $20 \%$ or less of new cable procurement cost.

\subsubsection{Cable Retirement}

Exact criteria for retiring a cable are difficult to

postulate. Experience and judgement are certainly important. The following considerations may prove to be helpful.

Obviously if the worn end of the cable has been cut and reterminated many times, then the cable becomes too short to be useful and the remaining length, even if still in good shape must be discarded, at least for CTD operations. In other cases retirement must be based on tests, thorough inspection and review of the cable history.

Defects which should force cable retirement include:

- Loss of signal due to short or open circuits located at cable mid-length, or distributed along the cable length.

Loss of strength as established by actual tests. If the remaining strength is $25 \%$ (or more) smaller than the original breaking strength, then the cable should be retired.

- Reduction of metallic area. If the cable diameter is reduced $5 \%$ or more from its original dimension (as established by the acceptance testing) the cable should also be retired.

- External signs of bad deterioration, such as extensive rust broken armor wires, bird cages, loose armor, etc.

Another cause for retirement should be the cumulative number of cycles under high tension. The number of times certain sections of the cable have been used under high tension should be readily available from the cable 
life history records. If the number of cycles and the tension levels come close to values at which similar cables are known to fail, then retirement of the cable should be seriously considered. On the other hand if the used cable has been subjected to only a few high tension cycles and/or does not have the defects mentioned above, then reconditioning should be considered.

\subsection{Winch Maintenance and Winch Monitoring Instrumentation}

Again it is beyond the scope of this report to present a systematic review of the maintenance procedures specific to the different types of winches used for CTD lowering applications. These are best found in the maintenance schedule provided by the winch manufacturers. On the other hand the following remarks may well be helpful to any winch maintenance program.

Documentation. Both scheduled and exceptional maintenance operations should be recorded in a winch maintenance 1 og. This practice would help ensure operational continuity and good preventive maintenance. Breakdowns, repairs, changes of parts, oiling and greasing, calibration of winch sensors, tests, etc... should be recorded in this log. A format for such a $\log$ is suggested in Appendix 6 .

- Shipboard Maintenance. Shipboard maintenance essentially consists of regular inspections and preventive maintenance. Before departing for a cruise and thereafter at regular intervals the condition of CTD winches should be carefully inspected. This inspection should include a check of the oil quantity and quality in a11 gear boxes. If saltwater or metal chips are found in the oil, causes of leak and wear should be detected and corrected. Electrical motors should run smoothly. Brushes should be checked. 
Overheating while running should also be monitored. Ascertaining the good performance of the hand brake is another important part of the winch inspection. This brake which is used in emergencies such as failure of the automatic brake, or the clutch, or the gear train must be in excellent working condition. Its holding must be checked by actually working it against the winch. Both the automatic (magnetic) and hand brakes must be regularly inspected for signs of wear and tear of their drums and 1iners.

The clutch controls should be free to operate. The locking pins which normally keep linkages in place should be checked as to their presence and condition.

The level wind diamond thread, the fairlied sheave and rollers should be checked for freedom of motion and signs of wear. Preventive maintenance at sea consists of regularly lubricating all exposed moving parts and bearing surfaces, filling all grease fittings, and replacing worn or broken parts as required. Shore Maintenance. After long cruises or extensive periods of use the CTD winches should be taken off the ship, removed to a shop ashore, and taken apart. A11 moving parts should be inspected for wear and deterioration due to fatigue and corrosion, and replaced as necessary. After reconditioning the winch should be fully tested and declared fit for further use at sea.

A11 CTD winches should be instrumented to monitor and optionally record cable speed (meter/minute), length of cable paid out (meters) and cable tension ( $1 \mathrm{bs}$ ). The instrument readouts should be digital and easy to read. Repeaters should be installed as necessary.

The acquisition of these data is required for the following reasons: 
1. To document scientific operations.

2. To observe and prevent excessive conditions which would degrade scientific work or damage the cable.

3. Provide cable usage record.

4. Provide data for the design of improved systems (e.g. accumulators, etc....).

5. Provide factual data to update limits on CTD casting depths and payout rates.

In addition visual (red light) and audio (be11) alarm signals should be available when either the tension reaches dangerous values or when the instrument is nearing the surface thus preventing accidental two blocking.

\subsection{Operational Limits}

\section{5 .1 Depth Limits}

Maximum cable tension occurs at the head sheave. As previously mentioned this tension depends on the length of cable paid out, the weight and shape of the payload, the prevailing sea state and the hauling speed.

Whatever the actual condition of use may be this tension should not be permitted to exceed a value corresponding to a safety factor of two for most applications, and in no case larger than the yield strength of the cable (about $75 \%$ of cable breaking strength for most data logging cables). To insure that this limit is not exceeded, fast response tension monitoring equipment with a good graphical (chart recorder) or visual (digita1) display should be provided for al1 CTD cruises and the tension should be monitored while lowering and retrieving the CTD package.

To help in planning safe lowerings, predictions of tension levels should also be available. These predictions could be made with the help of deterministic or stochastic models (References $3,4,5,6$ ). Results obtained 
from these models should be presented in a form easy to read. As an example, computations of maximum tension at the head sheave of the $R / V$ ATLANTIS II have been made using the analytical approach described in Appendix 7. Results from these computations, based on the use of Morison's formula for drag and inertia forces, are presented in graphic form in Figures 2, 3, 4 and 5. Graphs of tension versus length and hauling speed have been drawn for three different sea states (flat calm, and sea states 3 and 6). The maximum length that the cable can (or should) have for a given sea state and a given hauling speed can be easily found from the intersection of tension curves with the safe load ( $50 \%$ of RBS) or the yield strength ( $75 \%$ of RBS) lines. Curves similar to these could be computed and drawn for ship heave and roll amplitudes other than those assumed in this illustrative example.

\subsubsection{Speed Limits}

As previously mentioned, should the rate of fall of the cable be larger than the instrument terminal velocity, then the cable will become slack and kinks will be likely to occur. A knowledge of the instrument actual terminal velocity and a prediction of the head sheave vertical speed for different sea states conditions would help determine the maximum allowable payout rate.

Simply stated, if " $r$ " is the allowable payout rate, $V_{T}$ the instrument terminal velocity, and $S$ the sheave vertical speed, then the equation

$$
\mathrm{r}=\mathrm{V}_{\mathrm{T}}-\mathrm{S}
$$

should remain satisfied.

The nature of ship response to random seas makes exact predictions of sheave speed difficult. On the other hand conservative speed values can be estimated. The terminal velocities of instrument packages can be readily measured, (See Appendix 8). Therefore a reasonable estimation of payout 
PEAK TENSION@THE HEAD SHEAVE VS.

LENGTH OF CABLE PAID OUT

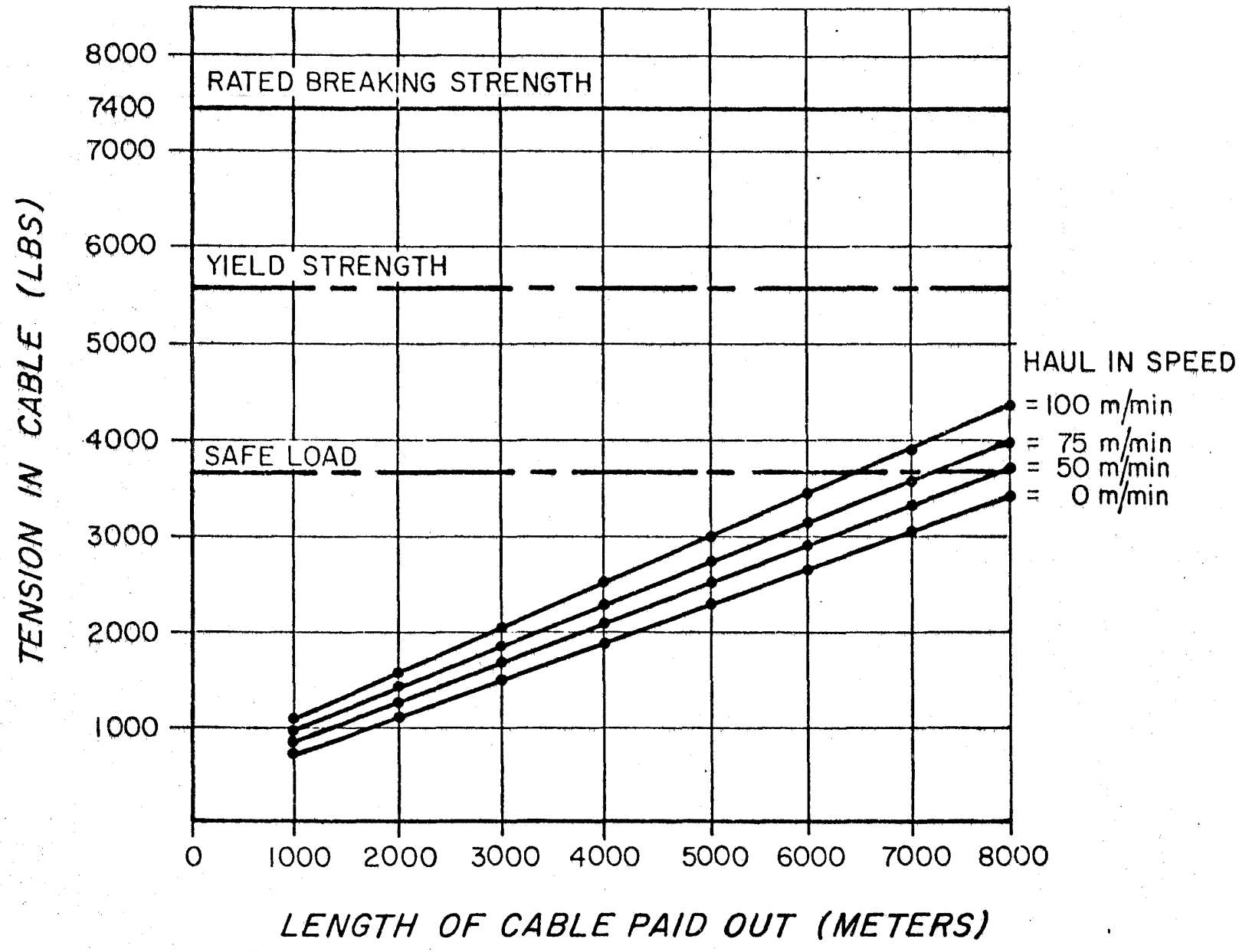

Figure 2

SEA STATE 0

Period $=$ N.A.

Heave Amplitude $=0.0$

Angle of Roll $=0.0$

Cable Characteristics:

$\mathrm{Wt} / 1000^{\prime}=145 \mathrm{lb}$.

Diameter $=.303$ inches

Drag Coeff. $=.01$

RBS $=74001 \mathrm{~b}$.
Instrument Characteristics:

Immersed wt. $=350 \mathrm{Ib}$.

Drag Constant $=9.72 \mathrm{ft}^{2}$

Virtual Mass $=21.0$ slugs 
PEAK TENSION @ THE HEAD SHEAVE VS. LENGTH OF CABLE PAID OUT

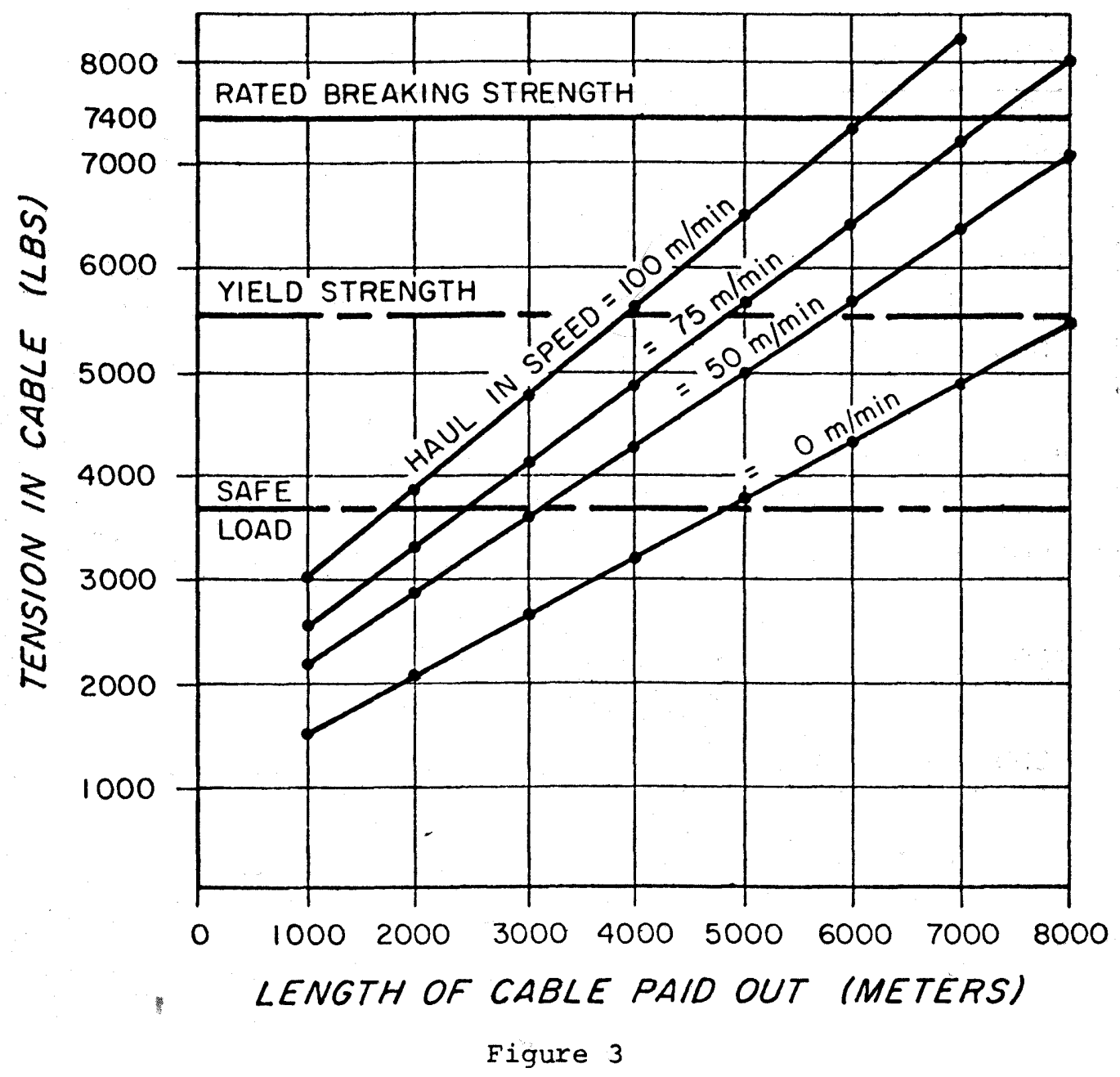

SEA STATE 3

Period $=8$ seconds

Heave Amplitude $=3$ feet

Angle of Roll = 15 degrees

Cable Characteristics:

$\mathrm{wt} / 1000^{\prime}=145 \mathrm{lb}$.

Diameter $=.303$ inches

Drag Coeff. $=.01$

$\mathrm{RBS}=74001 \mathrm{~b}$.
Instrument Characteristics: Immersed $W t$. $=3501 \mathrm{~b}$. Drag Constant $=9.72 \mathrm{ft}^{2}$ Virtual Mass $=21.0$ slugs 
PEAK TENSION @ THE HEAD SHEAVE VS. LENGTH OF CABLE PAID OUT

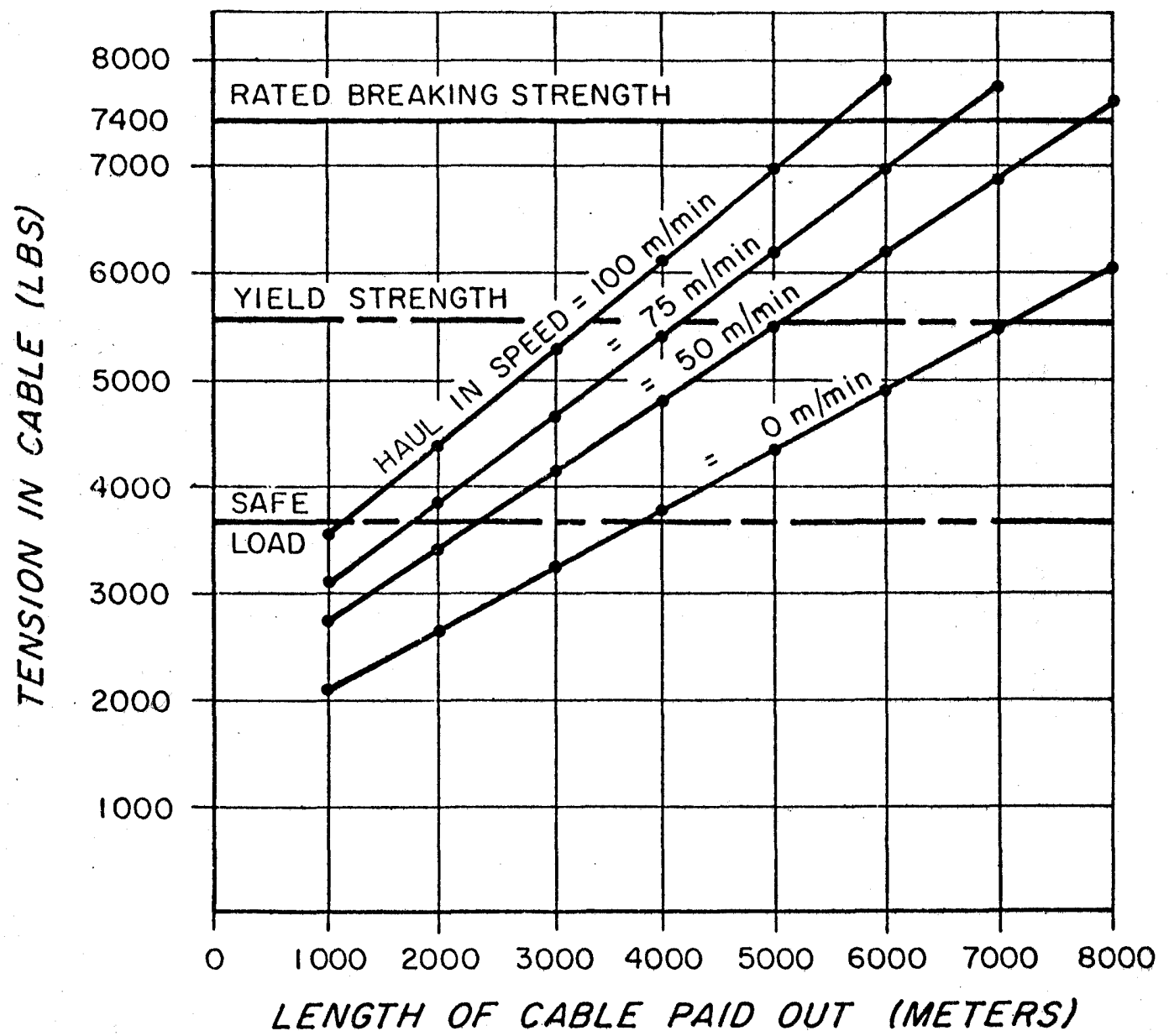

Figure 4

SEA STATE 3

Period $=8.0$ seconds

Heave Amplitude $=3.0 \mathrm{ft}$.

Angle of Roll $=15^{\circ}$

Cable Characteristics:

$\mathrm{Wt} / 1000^{\prime}=145 \mathrm{lt}$.

Diameter $=.303$ inches

Drag Coeff. $=.01$

$\mathrm{RBS}=74001 \mathrm{~b}$.
Instrument Characteristics: Immersed $W t .=850 \mathrm{lb}$. Drag Constant $=9.72 \mathrm{ft}^{2}$ Virtual Mass $=39.75$ slugs 
PEAK TENSION@ THE HEAD SHEAVE VS. LENGTH OF CABLE PAID OUT

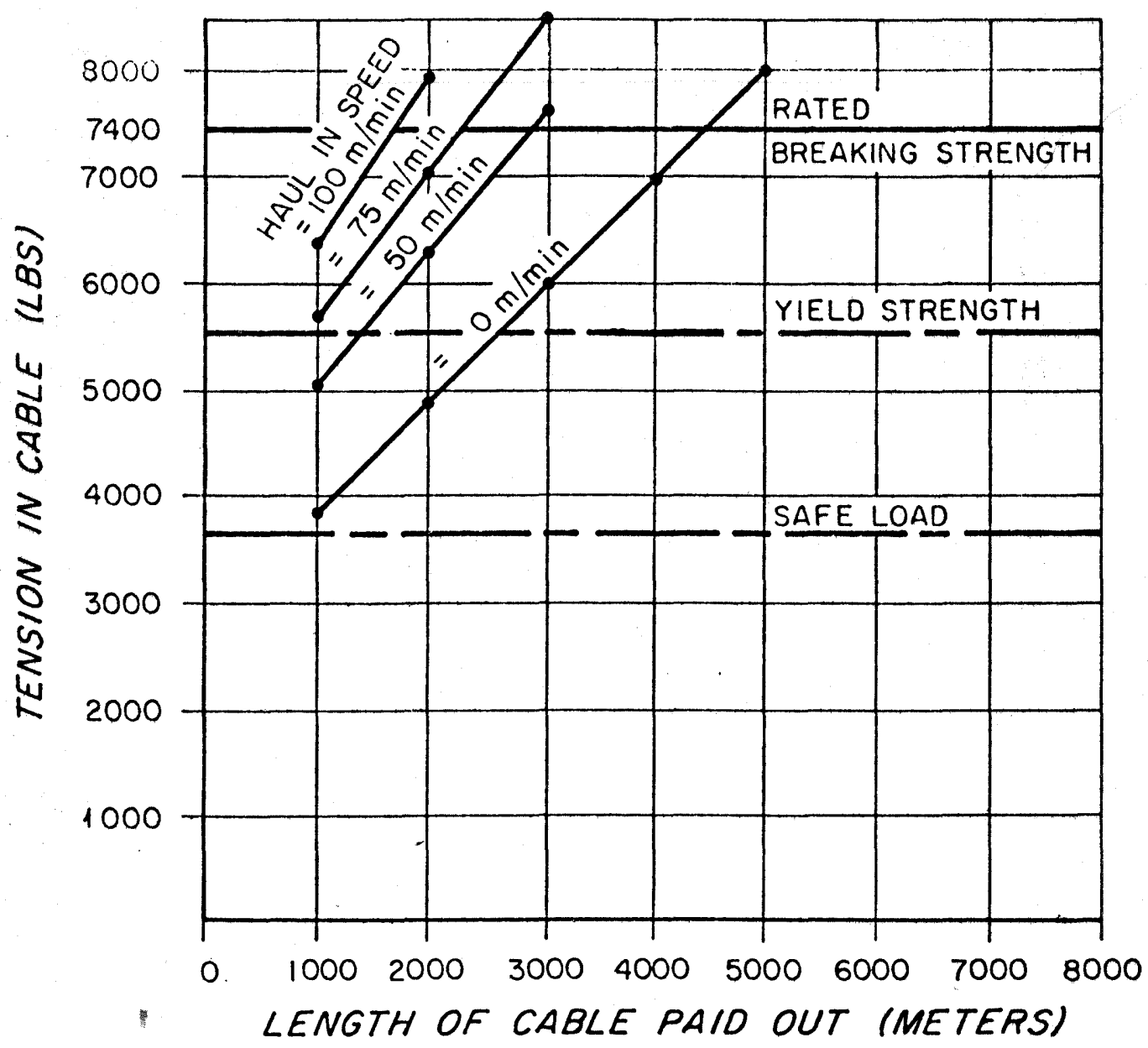

Figure 5

SEA STATE 6

Period $=10.0$ seconds

Heave Amplitude $=10.0$ feet

Angle of Roll $=30$ degrees

Cable Characteristics:

$\mathrm{Wt} / 1000^{\circ}=145 \mathrm{lb}$.

Diameter $=.303$ inches

Drag Coeff. $=.01$

$\mathrm{RBS}=7400 \mathrm{Ib}$.
Instrument Characteristics: Immersed $\mathrm{Wt} .=350 \mathrm{1b}$. Drag Constant $=9.72 \mathrm{ft}^{2}$ Virtual Mass $=21.0$ 
rates can be made based on this information. As an example, the following table lists the allowable payout rates computed for a CTD instrument package with a measured terminal velocity of 110 meter $/ \mathrm{min}(6.00 \mathrm{ft} / \mathrm{sec})$ and an immersed weight of 380 lbs. Table I points out that the relatively sma11 terminal velocity of this particular instrument severely limits the speeds at which it can be safely lowered.

\section{TABLE I}

Table of allowable payout rates (meters/minute) as a function of amplitude of ship heave ( $f t$ ) and rol1 (degrees) for an instrument with a terminal velocity of 110 meters/minute lowered from the R/V ATLANTIS II. (Period of roll $=8$ seconds $)$.

Rol1

Heave (feet) (degrees)

\begin{tabular}{|r|r|r|r|r|r|r|r|r|r|r|}
\hline & 0 & 1.0 & 2.0 & 3.0 & 4.0 & 5.0 & 6.0 & 7.5 & 10.0 & 15.0 \\
\hline & 110 & 96 & 81 & 67 & 53 & 38 & 24 & 2 & & \\
\hline 5 & 75 & 60 & 46 & 32 & 18 & 3 & & & & \\
\hline & 50 & 25 & 11 & & & & & & & \\
\hline
\end{tabular}

One way to increase the terminal velocity of a CTD package is to increase its immersed weight. If, for example, the immersed weight of this instrument was increased from 380 lbs to 850 lbs without appreciably changing its drag characteristics, then its terminal velocity would be 171 meters/minute $(9.35 \mathrm{ft} / \mathrm{sec})$. The effect that this terminal velocity increase has on the allowable lowering rate is reflected in Table II. The sma11 effect that the increased weight has on the peak tension at the sheave, for sea state 3 conditions, can be seen by comparing Figure 3 with Figure 4 , 
TABLE II

Table of allowable payout rates (meters/minute)as a function of amplitude of ship heave ( $f t$ ) and roll (degrees) for an instrument with a terminal velocity of 171 meters/minute lowered from the R/V ATLANTIS II. (Period of roll = 8 seconds).

\begin{tabular}{|c|c|c|c|c|c|c|c|c|c|c|c|}
\hline & & $\begin{array}{r}\text { Heave } \\
0\end{array}$ & $\begin{array}{l}\text { Eeet) } \\
1.0\end{array}$ & 2.0 & 3.0 & 4.0 & 5.0 & 6.0 & 7.5 & 10.1 & 15.0 \\
\hline \multirow{5}{*}{$\begin{array}{c}\text { Roll } \\
\text { (degrees) }\end{array}$} & 0 & 171 & 157 & 142 & 128 & 114 & 99 & 89 & 63 & 28 & \\
\hline & 5 & 138 & 122 & 103 & 93 & 79 & 64 & 50 & 28 & & \\
\hline & 10 & 101 & 87 & 72 & 58 & 43 & 29 & 15 & & & \\
\hline & 15 & 68 & 51 & 37 & 23 & 8 & & & & & \\
\hline & 20 & 31 & 16 & 2 & & & & & & & \\
\hline
\end{tabular}

To insure that safe lowering speeds are used at sea, the terminal velocity of all CTD packages should be measured at the dockside prior to departure. This information could then be used to compute the maximum payout rates for different heave and roll amplitudes. These results could then be tabulated in a manner similar to the ones shown, and used by the Chief Scientist as guidelines to establish safe lowering speeds. 


\subsection{Alternate CTD Lowering Systems}

It seems obvious that the present system limitations impact upon the quality and quantity of scientific observations. Both depth and speed limits specified by sea conditions are restrictions that should be reduced. Failures may be prevented by proper maintenance and inspection procedures but they will not be eliminated until the complete system is matched to the enviromental excitation of the motion of the vessel.

Several components of the system can be improved through modification, additions or replacement. A lighter cable would reduce tensions due to the cable weight. Reduced spooling tension at the drum will lessen the adverse effects to the cable due to crossovers. Reduced spooling tensions can be achieved through the use of a cable hauler. The use of an accumulator can reduce peak tension changes due to ship motions. Only winches with precision power driven level winding systems should be employed. The CTD package itself should be critically examined in the light of its hydrodynamic performance.

\subsection{Review of Possible E/M Cable Candidates}

The majority of CTD system failures involves damage or failure of the $E / M$ cable. This is not necessarily due to cable deficiencies as most cable failures have other contributing factors such as too high or too low tension or spooling damage. It follows that any improvements which can be made to the cable in terms of its torque characteristics, strength-to-weight ratio and conductor reliability will better resist failures from these contributing factors. Practically all users limit their cable selection to a very few types. A11 contain contrahelically wound steel wires as an inner and outer armor. Torque balance is achieved through the proper ratio of lay lengths of the outer-to-inner armor layers. Torque balance is also obtained through the use of smaller outer wires than inner wires. Copper 
conductors in various number and configurations have been used.

The history of failures as mentioned earlier include factors such as bending fatigue, kinking, axial loading fatigue, corrosion effects, wear and crushing. Most of these factors ultimately cause the electrical conductors to degrade in performance or fail. Candidate cables which may offer better performance will be examined.

\subsubsection{Special Stee1 Armor Cables}

An armored cable has been constructed* using the basic $3 \times 19$ oceanographic rope construction wherein the central wire of each strand was replaced by an insulated copper conductor. This novel cable has had limited but successful use in a $3 / 8^{\prime \prime}$ configuration. Manufacturing difficulties may preclude this cable in smaller sizes. The construction provides excellent torque-balance, low elongation and high strength.

Another approach which maximizes the strength-to-weight ratio thereby reducing tension values is to taper or sectionalize the strength member in the cable. Appreciable weight savings with a reduction of cross section area are possible using this technique.

Additional layers of armor can be added to standard contrahelical armored cable to increase its strength. However cross-sectional area is increased and the torque characteristics degraded.

\subsubsection{Synthetic Fiber Cables}

There are many advantages to the use of materials other than steel for lowered instrument applications. Cables made from synthetic fibers would weigh appreciably less and be free of corrosion. On the other hand most synthetic cables have considerable elasticity, more than the copper conductors necessary for data transmission. It is seldom possible, even with special designs, to obtain elongations greater than $1 \%$ in the *U. S. Steel Co. 
conductors suitable for use in a data logging cable (Reference 7).

With the introduction of Kevlar, a new material is available for use in rope and composite electromechanical cables. Kevlar is an aramid fiber manufactured by the duPont Company having unique properties of a high strength-to-weight ratio (for equal strength a Kevlar rope weighs less than $1 / 5$ that of a steel rope), non-corrosive, low elongation, and a high fatigue life. The material however does have a low transverse modulus, exhibits no yield point and is adversely affected by internal or external abrasion.

Swenson (Reference 7) has conducted extensive tests on different rope configurations and designs to optimize the mechanical and electrical characteristics of a cable suitable for an electrical tension member. Designs have been constructed and tested using special twisted conductors which in turn are twisted into pairs, triads and quads to provide elongation characteristics similar to the Kevlar strength member. In these ropes the Kevlar was braided around the electrical conductors. This overbraid construction of Kevlar provides a permanent stretch after elongation which reduces the problem of conductor hockling or buckling upon the release of tension. Another approach may be to use a wire rope construction which exhibits on1y a small amount of elongation and reduces the Kevlar cross-over stresses common to braid constructions.

It now appears that a Kevlar electromechanical cable could be constructed which would be light in weight and non-corrosive. A development and test program should be initiated to build upon the work done to date to establish the best construction technique for a cable for the CTD application.

\subsubsection{Fiber Optics Cables}


for CTD lowering applications are hereafter reviewed. Several advantages are to be gained by the use of fiber optics as signal carriers: reduced signal attenuation, possible reduction of the salt water short problems, freedom from electromagnetic interferences, elimination of cross talk, and above al1 increased data transmitting capabity. The inability to send power via fiber optics is a drawback which can be overcome by use of hybrid cables. On the other hand the tension, flexing and twisting that optical fibers experience during cable use introduces stresses which can severely damage the fibers - a problem yet to be resolved, particularly if the cables are to be used with standard shipboard winches and sheaves.

A considerable research and development effort is presently underway by the communication and cable industry. Most of this effort concentrates on the use of fiber optics cables for underground, or in the oceanographic context, for bottom implanted fixed installations. Experimental fiber optics cables have been developed by the Naval Ocean Systems Center (NOSC) in Kailua, Hawaii, for underwater television. This research effort might we11 culminate, within the next few years, in a new generation of lightweight fiber optics cables suitable for CTD lowering applications.

The main components of fiber optics cables are the optical fiber core, the buffer, and the strength members. The optical fibers (thin fibers of an extremely pure dielectric or glass material drawn to lengths of several kilometers) transmit information in the form of light, modulated in some suitable way, and confined to the fiber by the phenomenon of total internal reflection. Buffers are layers or sleeves of insulating and protective material placed around the optical fiber case. Strength members are made of either steel wires or Kevlar fibers. Certain cable designs have the strength member at the center, with the optical fibers placed around it. The majority of cables, however, have the optical fiber at the center and 
the strength members on the outside. The optical and mechanical properties of optical fibers and the desirable features for the design and construction of CTD optical fiber cables are hereafter presented. Also included is a brief review of the different cable prototypes so far produced.

\section{Optica1 Properties of Fibers}

Optical properties of particular interest to signal transmission over long distances include:

Numerica1 Aperture. Optical transmission in fibers may be viewed as the propagation of a wave in a waveguide. For fibers of diameter considerably larger than the wavelength of light, the propagation may be viewed and understood as a process of trapping the light rays by total internal reflection. This is illustrated in Figure 6.

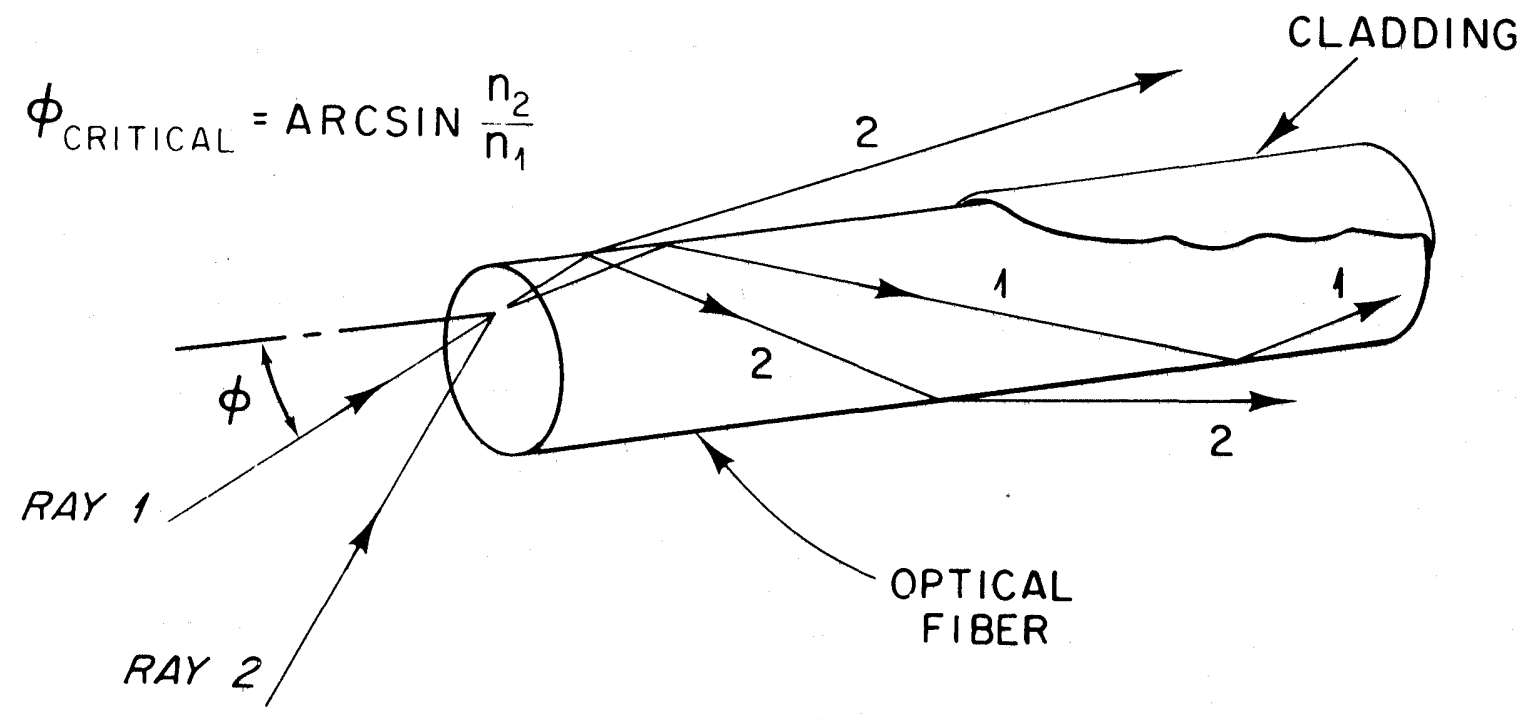

Figure 6 
Two rays, 1 and 2 , are shown. If the ray enters the fiber at an angle $\emptyset$ of less than the critical value, it is totally internally reflected, whereas ray 2 at greater than the critical value is partially reflected, partially transmitted and eventually lost. The critical value of $\phi,\left(\phi_{\max }\right)$ is determined by the refractive indexes $n_{1}$ of the fiber and $\mathrm{n}_{2}$ of the "cladding". The significance of $\phi_{\max }$ is that it determines the "numerical aperture" (NA) of the fiber. The NA, analogous to NA for lenses, is a measure of the light acceptance capability of the fiber. It is formally expressed as $N A=n_{2} \sin \phi_{\max }=\left(n_{1}^{2}-n_{2}^{2}\right)^{1 / 2}$.

Dispersion. It should be noted that rays other than those parallel to the axis travel a longer optical path, thus giving rise to the phenomenon of dispersion - broadening of the transmitted light pulse as observed at the receiver end. The "dispersion" is, obviously, greater for larger NA fibers. Thus a trade-off between light coupling efficiency and "pulse dispersion" exists. The dispersion is expressed in $\mathrm{nsec} / \mathrm{km}$. This dispersion arises in addition to "wavelength dispersion" or "material dispersion" for non-monochromatic light sources.

1. The total dispersion (i.e. material plus pulse) described above is the phenomenon which puts the upper limit on the frequency at which data may be transmitted. The ideal fiber would be one which shows a large NA for increased coupling of light, while at the same time a low dispersion. To reduce dispersion, and hence increase bandwidth, graded-index fibers were designed (in contrast to the "step-index" described in Figure 6 ). In such a fiber, the fiber extrusion process is modified to produce a gradation in the index of refraction in the radial direction. A typical ray in this fiber bends into the fiber due to the radially decreasing refractive index. The rays are thus made more parallel to the fiber axis equalizing paths thus reducing dispersion. Since optical path is the product of geometrical path 
and refractive index n.s., a reduction in $\mathrm{n}$ away from fiber axis further reduces dispersion. Typical dispersions obtained for these graded index (GI) fibers are 1 to $3 \mathrm{nsec} / \mathrm{km}$ whereas the corresponding figures for stepindex (SI) fibers are 10 to $30 \mathrm{nsec} / \mathrm{km}$. The ray path for such a GI fiber may be computed according to the Eikonal equation (Reference 8). Although this discussion suggests strictly linear increase in dispersion with length, the phenomenon of mode coupling - energy exchange between different modes of the electromagnetic field - reduces the dispersion for very long fibers, while increasing losses.

Fibers, the diameter of which is much larger than the wavelength, permit light to propagate in several modes. These are called multimode fibers. Fibers with diameter of the same order as the wavelength of light are also being made. These are called single mode fibers, and as is evident in these fibers only a single mode may propagate.

The propagation of light in such fibers is treated by rigorous solutions of Maxwe1l's equations, and can be found in any of the standard references (References 8 to 10). Propagation of a single mode (i.e. a single axial ray) occurs when the "normalized" frequency parameter V given by

$$
V=\frac{\pi d}{\lambda}\left(\eta_{1}^{2}-\eta_{2}^{2}\right)^{\frac{1}{2}}
$$

where $\mathrm{d}$ is the fiber diameter and $\lambda$ is the light wavelength, is less than 2.405 .

Single mode fibers have inherently small NA and due to their extremely smal1 diameters (e.g. if $\mathrm{n}_{1}=1.48, \mathrm{n}_{2}=1.46$ then at $\lambda=0.82 \mu \mathrm{m}, \mathrm{d}=$ 2.6 $\mathrm{m}$ ) splicing, light coupling and connector preparation are severe problems, making their use at present limited to laboratories. This situation is however, changing very rapidly. Conceivably, future usage will be found for the extremely high bandwidth due to the zero intermodal dispersion of a 
single mode fiber.

Intermodal pulse broadening is absent in single mode fibers. However wavelength dispersion which arises from changes in refractive index with light wavelength will be present if a nonmonochromatic light source is used. This dispersion is minimized in glasses when the wavelength ranges between 1.2 and $1.3 \mu \mathrm{m}$, the precise value depending on the material used. Attenuation. Losses in fibers result from absorption and scattering by the glass material and imperfections and microbending in the outer surface.

Losses are predominantly due to Rayleigh-scattering at short wavelengths $(0.4-0.8 \mu \mathrm{m})$. Losses due to Raman and Brillouin scattering, though present are a few orders of magnitude weaker. Losses due to oH radical absorption occur at longer wavelengths, near the infrared region. The oH spectral absorption bands appear at $0.825,0.825,0.875,0.950,1.24$, and $1.39 \mu \mathrm{m}$ and result from the fundamental $\mathrm{OH}$ vibration band at $2.73 \mu \mathrm{m}$ and overtones in the silica matrix (Reference 8 ) roughly adding $1 \mathrm{db} / \mathrm{km} / \mathrm{ppm}$ to the attenuation at $0.95 \mu \mathrm{m}$. Absorption due to metal ions are currently negligible lin comparison. In fact, to prevent possible long term degradation of fiber performance due to molecular diffusion of $\mathrm{OH}$ from environmental water content, metal coatings have been suggested on top of the cladding. The typical variation of attenuation as a function of wavelength is shown in Figure 7 . Clearly, operation at wavelengths of 1 to $1.5 \mu \mathrm{m}$ appears advantageous due to reduced 1oss. A single mode system using no repeaters over a $53.3 \mathrm{~km}$ length, transmitting $32 \mathrm{Mbit} / \mathrm{sec}$ was described in a paper presented at a recent meeting (Reference 11). To obtain low loss and low dispersion, transmission at 1.2 and $1.6 \mu \mathrm{m}$ was used with germanium phosphosilicate fibers. Another system (Reference 12) described at the 


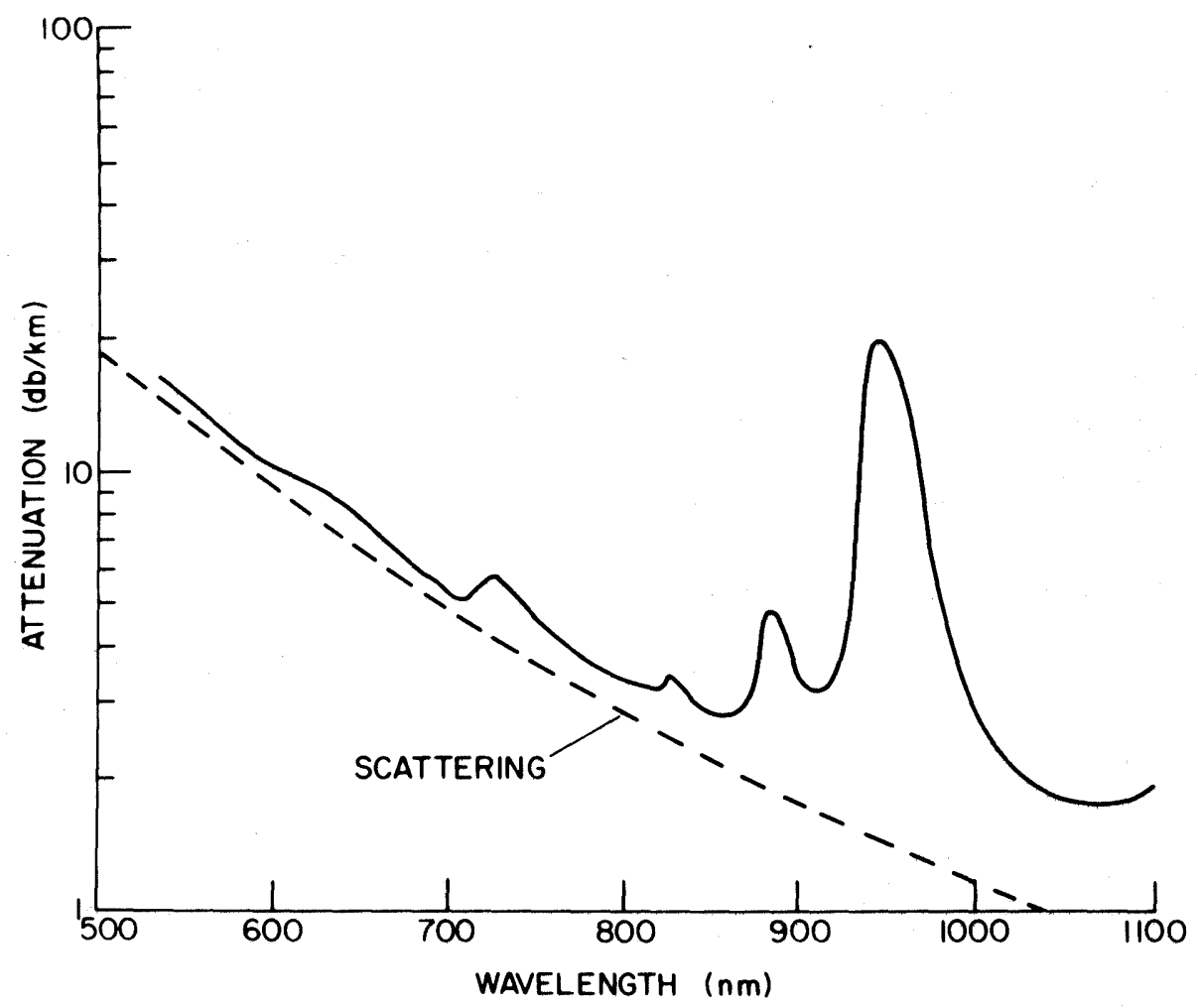

Figure 7. Attenuation as a Function of Wavelength 
same meeting used single mode fibers with losses of only $0.2 \mathrm{db} / \mathrm{km}$ at $1.55 \mu \mathrm{m}$ - almost at the 1imit of $0.18 \mathrm{db} / \mathrm{km}$ considered theoretically achievable. New, $\mathrm{G}_{\mathrm{e}} \mathrm{O}_{2}$ based fibers under development at Corning are estimated to have intrinsic losses of only $0.15 \mathrm{db} / \mathrm{km}$ at a wavelength of $1.6 \mathrm{\mu m}$.

\section{Mechanical Properties of Fibers}

The successful use of optical fibers to manufacture fiber optics cables depends to a large extent on the mechanical properties of the fiber, such as elastic modulus, strain at break, resistance to abrasion and chemical attack and attenuation at high pressure, etc. Since optical fibers must withstand the strain suffered by the load bearing member, high strain capability becomes essential. Concomitant with this is the requirement of high tensile strength.

Pristine glass fibers are extremely strong, as is evident in Figure 8 . Considerable $\mathrm{R} \& \mathrm{D}$ effort is being spent on improving fiber strength (indicated by special sessions devoted to the topic at the OSA/IEEE Topical Meeting in Washington, D.C. 1979). A review of the state-of-the-art was 1. published by Maurer in 1977 (Reference 13), and an update was presented by Kurkjian (Reference 14).

The strength of fibers depends on several factors, such as the quality of the preform rod used in drawing the fibers, the purity of the furnace environment, temperature of draw, tension at draw and exposure to atmosphere. Low draw tension produces strong fibers, high temperature of draw causes fusion at the surface reducing the probability of appearance of microcracks and improving the fiber strength. An indication of the ultimately achievable strength of $6 \times 10^{5} \mathrm{psi}$ shown in Figure 9 . This value is approximately 2 to 3 times the strength of current steel wires. The "proof test" strength of present fibers is typically $1 \times 10^{5}$ psi. A method being investigated to increase fiber strength is to apply a cladding which induces precompression 


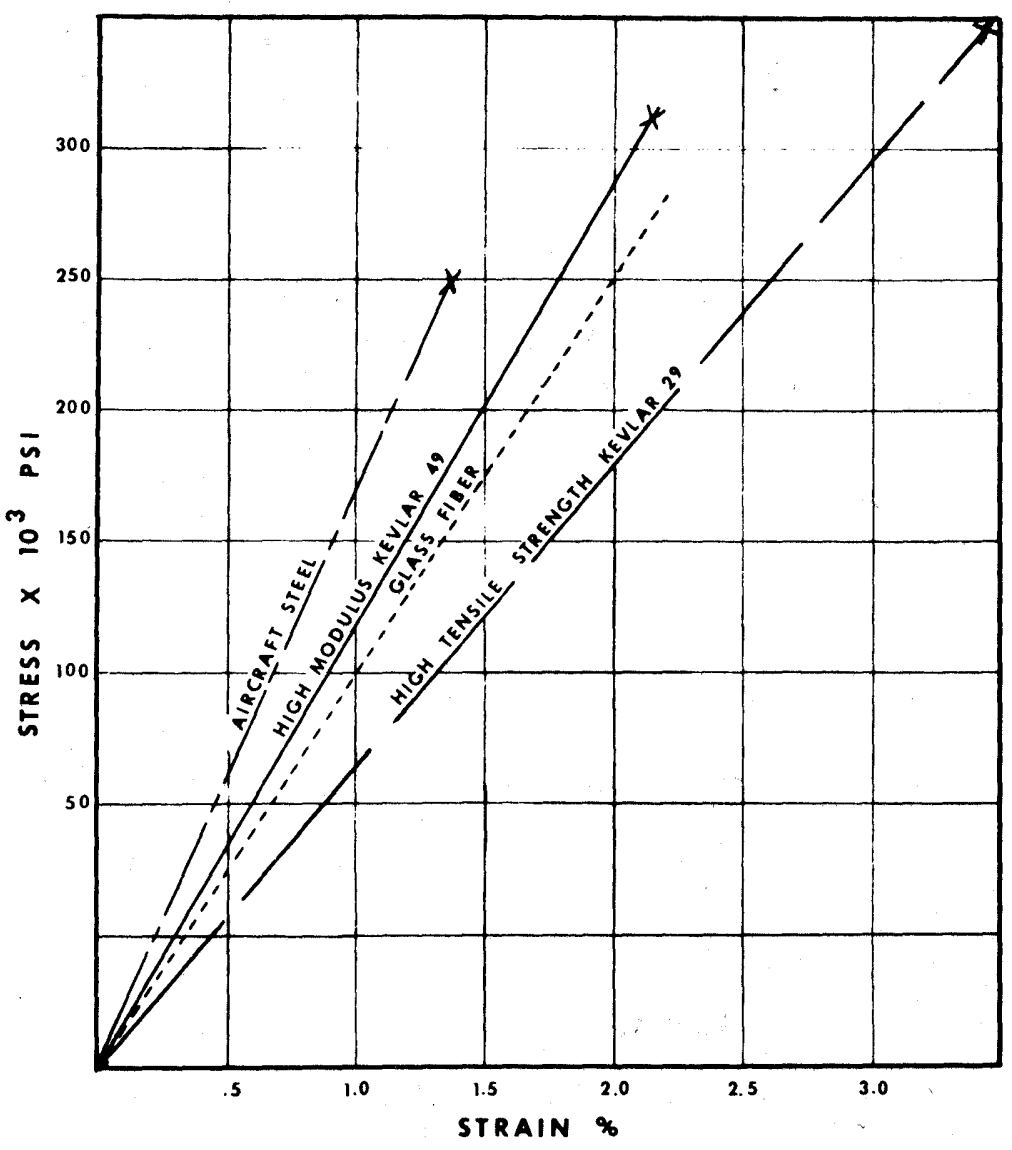

Figure 8 
TENSILE STRENGTH, GN/m²

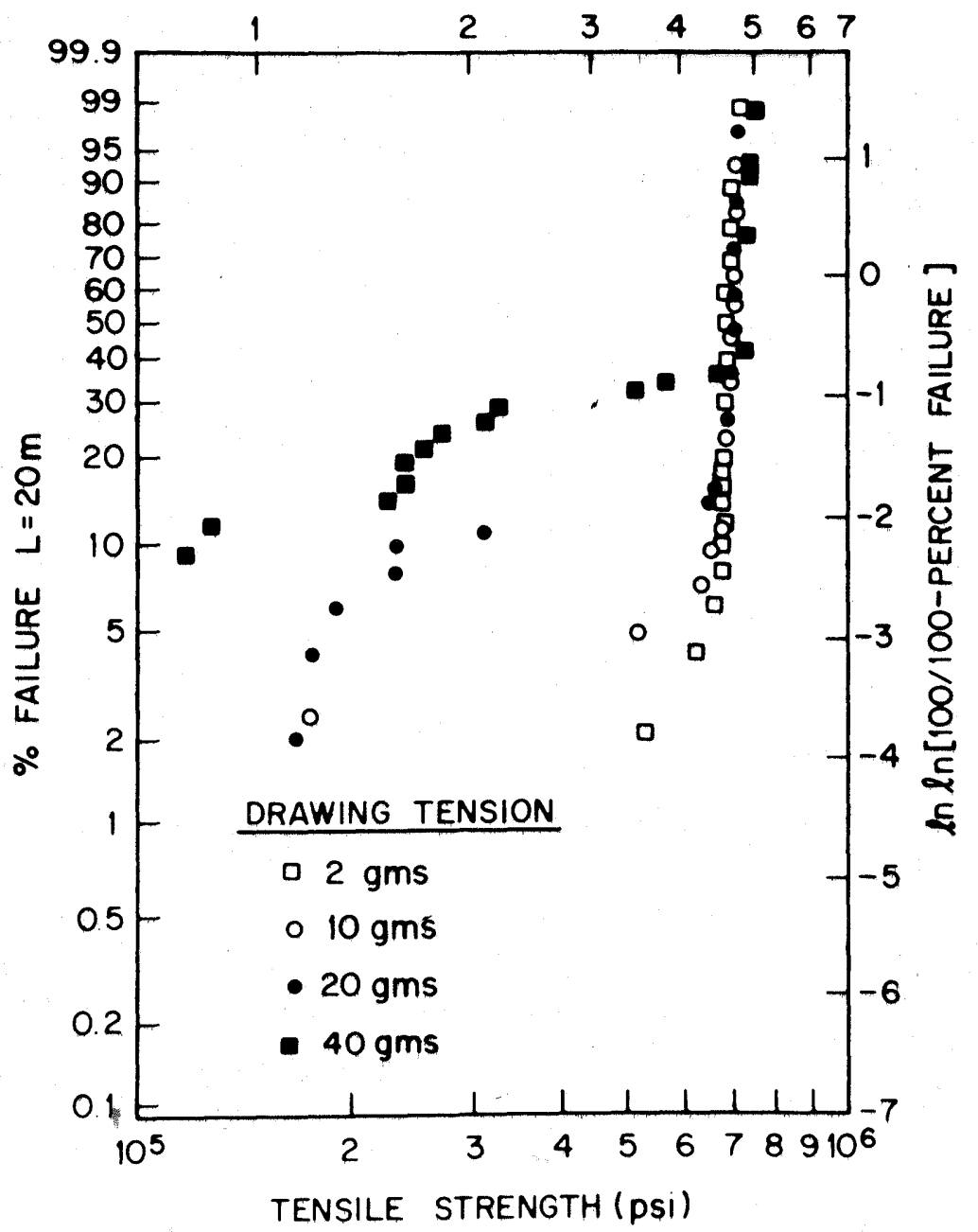

Figure 9 
stresses in the drawing process (Reference 15). Fiber strength has also been studied as a function of aging under load - up to a $50 \%$ increase was reported (Reference 16). Low $\mathrm{pH}$ was found less offensive to fiber strength. Static fatigue - i.e. failure after long periods at relatively low stress due to stress corrosion at flaws in the presence of moisture is a major mode of fiber failure. In essence, in the presence of moisture, surface cracks propagate at stress levels we11 below the strength of the Si-O bond. An approach to overcome this problem, besides the coating of low moisture-permeable plastics, is the metal coated fiber. The metal sheath hermetically seals the fiber and has proven to be an effective barrier, increasing static fatigue life-time by orders of magnitude over those for plastic coated fibers. Metal coatings usually are accompanied by higher fiber attenuation. On the other hand metal grain-boundary corrosion and metal jacket fatigue in cyclic stresses are problems inherent in this process.

\section{Cable Design/Manufacture Considerations}

The desirable features for the design and construction of future CTD optical fiber cables include:

Light Weight. The combined effect of cable weight and acceleration places a severe constraint on the maximum length of present CTD casts. A reduction of weight would certainly help remove this operationa1 1imit.

Resistance to Sea Water. The optical fibers should be protected by a watertight barrier from the corrosive effects of sea water. Armor wires, if any, should also be protected from the effects of corrosion.

Resistance to Pressure. External pressure, hydrostatic or due to cross winding, applied to the cable may result in sma11 deformations of the optical fibers. Voids in the fibers or in the buffer matrix and/or 
cable armor laying imperfections introduced by loose wire-size tolerances or stranding process will cause microbending of the fibers when subjected to external pressure. As previously mentioned microbending of the fibers causes the light to scatter thus contributing significantly to signal attenuation, (Reference 17 ).

Resistance to Cyclic Bending. The cable should be able to withstand repeated bending over sheaves and winch drums of reasonable sizes, while subjected to full working loads, without deterioration of strength or excessive increases in signal and attenuation.

Strength Member Elasticity. To ensure that the optical fibers are not subjected to excessive tensile loads the Young's modulus of the strength member should be higher than that of the fiber. The strength member should also be designed to avoid slippage or telescoping of the fiber core within the armor.

Cabling Process. The cabling process can induce tensile, torsional and flexural stresses depending on the fabrication procedure. If the fibers are tightly wrapped around a central strength member, they h will be under tension. Torsion may arise if fiber twist is not compensated in helix laying. The small bending introduced in laying the helix introduces flexural stress. Most significantly, microbends due to imperfections in helix winding of the support member may increase fiber loss very significantly. It is due to this excess loss caused by microbending that this fabrication procedure is the less preferred. Paraxial stress members have proven more suitable.

Survey of Experimenta1 Fiber Optics Cables. A number of fiber optics cables have been developed for overland communication systems, the incentive being the substantial cost savings obtained. In these applications weight is not a drawback and therefore the well established technique 
of stranding steel wires to provide core protection and cable strength has been used to fabricate these cable prototypes. Some of the companies involved in this development effort include Simplex Wire and Cable, International Telephone and Telegraph (ITT), Optelecom, Vector Cables, Rochester Cable Corporation, and Boston Wire and Cable.

Simplex is actively pursuing the development of transatlantic cables for the Bell Telephone System. Types of fibers, buffer, and cable construction are discussed in Reference 18.

ITT attempted to develop a hybrid cable for the Naval Research Laboratory. These cables contain both optical fiber and copper conductors. Failure of optical fibers due to excess strain while cabling as well as excessive signal attenuation were experienced with this cable. The development at present appears to be sta1led.

Optelecom of Gaithersburg, Maryland, offers as a standard product a steel armored single fiber cable in two strengths, 1200 lbs $(0.125$ in diameter): and $2800 \mathrm{lbs}$ (0.185 in diameter). Performance of these cables is stil1 being evaluated.

Vector Cables is testing an 8000 lbs rated strength, 0.46 in diameter, in a one fiber and seven conductor configuration.

In general, complete test data and user experience are not available on most of these experimental steel cables. However this picture is likely to change in the near future.

The development of cables specifically designed for oceanographic applications has been pursued by Galileo Electro-Optics and the Naval Ocean Systems Center (NOSC) Hawaii.

Galileo Electro-Optics of Sturbridge, Massachusetts, has been developing high strength cables for towed applications for NATO and the Defense Ministry of New Zealand. These two optical plus two electrical channel cables are to be $2 \mathrm{~km}$ (NATO) and $4 \mathrm{~km}$ (New Zealand)long and have a breaking strength of 
20,000 lbs. A step-index fiber is to be employed with specifications of $10 \mathrm{db} / \mathrm{km}$ at $0.9 \mu \mathrm{m}$ and a $15 \mathrm{nsec} / \mathrm{km}$ dispersion. The copper conductors are to carry one ampere at $1500 \mathrm{~V}$ DC. This development has chosen a helix wind approach for the fiber, and it is reported that with a $3 \frac{1}{2}-6$ " lay the cabling-caused increase in attenuation is less than $0.5 \mathrm{db} / \mathrm{km}$. However, microbending associated with tension tests has increased this figure by 10 to $15 \mathrm{db} / \mathrm{km}$. Further development with increased bedding (buffer) thickness between fiber and armor is in progress.

The most vigorous program in development and testing of lightweight cables of interest to oceanographic research appears to be at the Naval Ocean Systems Center (NOSC) Kailua, Hawaii. NOSC has abandoned steel armor due principally to the large self-weight. The NOSC approach is to use cables of low specific gravity, even neutrally buoyant. This reduces the strength required of the cable. This is done by using a combination of Kevlar-49 and S-Glass (a high modulus fiberglass), which have strength equivalent to steel but have a much smaller specific gravity. The mixture of Kevlar and S-Glass fibers is used to tune the elastic modulus of the 1. strength members.

A typical cable is shown in Figure 10. The strength member is made of $48 \%$ Kevlar $-49,10 \%$ of S'Glass and $42 \%$ of eopxy. The epoxy prevents the self destruction of Kevlar fibers by abrasion. This cable has an OD of $2 \mathrm{~mm}$ and a strength of 500 lbs. Initial difficulties with voids increasing attenuation under pressure have been partially overcome, to test pressures of $10,000 \mathrm{psi}$. The operational temperature range is $-100^{\circ} \mathrm{F}$ to $160^{\circ} \mathrm{F}$ (the upper limit is of interest due to high temperatures reached upon exposure to sun at sea). The cabling is done for NOSC by Air-Logistics of California. Test of an $8 \mathrm{~km}$ long cable on a stereo-TV are scheduled for early 1980 . (Private Communication with Frank Armogida, NOSC, Code 5334, Kailua, Hawaii, May 24, 1979). 


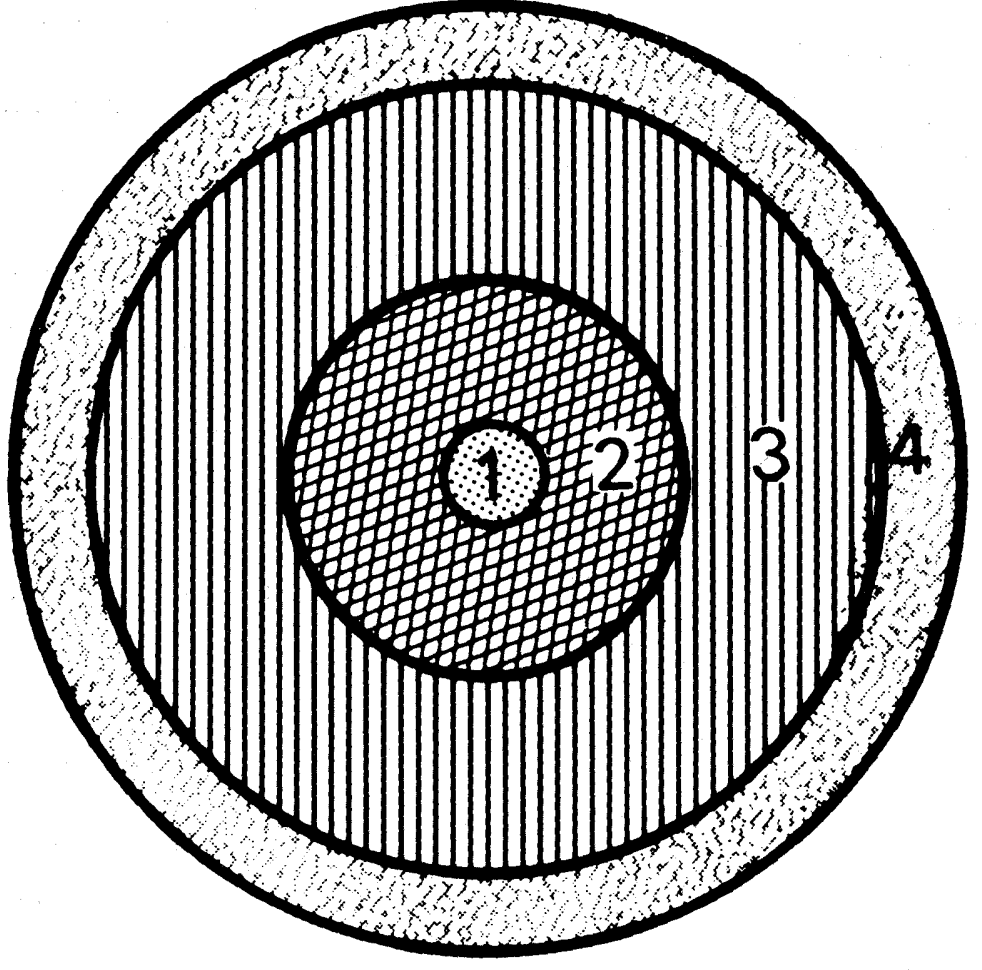

Figure 10. Cross-Section of Typical Fiber Optics Cable

1. $125 \mathrm{~km}$-diameter, low loss, graded index optical fiber (ITT-EOPD)

2. Annulus of Dow Corning Silicone resin (SYLGARD RTV-189) to nominal O.D. of $350 \mathrm{\mu m}$.

3. Annulus of DuPont Polyester elastomer (HYTREL 7248) to nominal O.D. of $0.5 \mathrm{~mm}$.

4. Load bearing annulus to $O . D$. of $1.25 \mathrm{~mm}$. Consists of paraxial filaments of DuPont KEVLAR-49 and/or Johns Manville HTS-901. S-Glass in matrix of Air Logistics 380-6 thermosetting epoxy resin. 


\section{Conclusion}

Vigorous development of both steel-armored and Kevlar strengthened fiber-optics cables is in progress. Routine production of reliable, fully tested stee1-armor cables is at present unknown. Comparatively lower strength Kevlar-S-Glass-Epoxy cables developed at NOSC, Hawaii, appears very promising. If the signal transmitting capacity of fiber optic cables is of real advantage to CTD users and if cable performance can be demonstrated by extensive tests reproducing the actual conditions of CTD lowerings, then clearly, in a not too distant future (5 years), fiber optics cables will find their place on board oceanographic research vessels.

\subsection{Redesign of CTD Instrument Package}

In the past little consideration has been given to the hydrodynamic performance of CTD instrument packages. The mechanical design has placed emphasis on strength to resist tension and pressure and on providing a frame for instrument protection and attachment of ancillary equipment.

Location of center of buoyancy and center of gravity, righting moment, dynamic stability during free fall, spin, hydrodynamic resistance, are performance factors which have been largely ignored. As a result most present CTD packages have a relatively low terminal velocity which severely limits lowering speeds and CTD use in rough weather, as already pointed out. Furthermore, measurements of instrument tilt angles and rotation (spin) which were recently made by the Canadian Bedford Institute of Oceanography (R. Reininger, personal communication), show that CTD instruments can severely kite and rotate as they sink. The impact that such motions may have on the quality of scientific data, particularly when looking at oceanic microstructures, has yet to be evaluated. An important recommendation of this report is to further study the hydrodynamic behavior of CTD packages, This study should point out the undesirable features of 
the present package configurations (including versions with water sampler rosette) and outline modifications which would improve the instrument overall performance. As part of this study a full scale prototype of the new package design should be made and its performance evaluated both at the dockside, and at the end of a lowering cable at sea. 


\subsection{Conclusions/Recommendations}

Recommendations to improve the reliability of present CTD lowering systems are hereafter summarized.

- E/M cables should be manufactured according to well written specifications. New cables should be carefully inspected and tested prior to installation. Cable testing equipment should be acquired.

- Winding new cables on winch drums should be done according to the procedure previously described in this report.

- E/M cables should be rinsed, and lubricated periodically when in use, and prior to long term storage.

- Records of winch/cable use, inspection, maintenance, and replacement should be kept to permit documentation of system use and history and to provide facts for retirement and/or system improvements .

- Winch level winding systems should be upgraded and maintained in the best possible way to ensure proper winding of cables on the winch drum.

- Blocks and sheaves should be of the proper size (sheave diameter and groove diameter) in order to minimize cable wear. Sheaves should be equipped with keepers to ensure that cables remain in the grooves, should they become slack.

- A11 CTD winches should be instrumented to monitor cable speed, length of cable paid out, and cable tension. Alarm signals should be available, as previously described. 
- For each vessel, calculations predicting cable tension versus heave and roll, hauling speed, and length deployed should be available in convenient graphic or tabular form. Likewise. calculations should be available of allowable pay out rates as a function of CTD instrument package terminal velocity and sea state.

- Limits of CTD lowering depth and winch speeds (pay out and hauling in should be set accordingly.

These recommendations can and should be implemented as soon as feasible. It is of interest to note that similar recommendations can be found in two recent reports on the subject of winches and shipboard equipment, one written by an oceanographic equipment workshop sponsored by UNOLS (Reference 19) and one by the University of Rhode Island, School of Oceanography (Reference 20).

To further improve the reliability and performance of future CTD systems we also recommend that:

- A special engineering program be initiated to obtain measurements of ship motion and tension levels at the sheave and at the lower end of the cable. These measurements would be used to validate mathematical models of payload lowering dynamics (References 5,6) which are necessary to predict tension levels and ascribe rational depth limitations. These data would also be used to better assess the need for the use of accumulators and eventually to design such accumulators. Measurements of the CTD attitude would be helpful for future CTD package design purposes.

- A study be made of the CTD package hydrodynamic behavior and that a new and improved package be designed and tested. 
- Progress in the development of fiber optics cables be closely followed. If greater data capacity (bandwidth) is required, then experimental lengths of fiber optic cables should be acquired and fully tested at sea.

- The use of Kevlar electromechanical cables be further investigated to eliminate corrosion effects and reduce cable weight. Winding machines and cable haulers should be investigated to provide low storage drum tension. 


\subsection{APPENDICES}

1. CTD Cable Fatigue Test Report

2. Evidence of Probable Cause of Kinking and Conductor Failure in CTD Lowering Cables ( $R / V$ KNORR Cruise 非3)

3. E/M Cable Specifications

4. E/M Cable Life History Documentation

5. Lubricant Data Sheet

6. Winch Documentation

(CTD (Acoustic) Winch Maintenance Log)

7. Computation of Peak Tension in CTD Cables at the Head Sheave of a Ship Undergoing Both Heave and Roll

8. Measurement of CTD Package Terminal Velocity

9. Spooling $\mathrm{E} / \mathrm{M}$ Cable on Smoothed Surface Drums 
APPENDIX 1

CTD CABLE FATIGUE TEST REPORT 


\section{APPENDIX 1}

\section{CTD CABLE FATIGUE TEST REPORT}

Purpose of Test. Investigate under controlled conditions the damage experienced by typical CTD cables when cycled under tension in a three whee1 test set-up duplicating shipboard installed dynamometers on WHOI Markey winches.

Test Description. The tests were performed at the Rochester Corporation Laboratory on November 23, 1977. Samples were mounted on a tension cycling machine and passed back and forth over three sheaves, one 6 inches and two $51 / 8$ inches in diameter, under loads from $26.4 \%$ to $67.8 \%$ of their breaking strength. Failure was defined as either conduction breakdown or break of one armor wire.

Test Results. Test results are summarized below.

\begin{tabular}{l} 
TRC 10291 \\
S1ighty \\
Corroded \\
\hline
\end{tabular}

OD

Breaking Str.,Lbs

(New)

(Used)

Cycling Test Load

(Lbs)

(\% Break.Str.)

Smallest Sheave

Size No.of Times

Larger than

Largest Wire Size

No. Cycles Until

Failure

Fai lure Type

.291

$9450 *$

2500

26.4

146

847

Armor
6000

67.8

2000

40.2

4974

6250

New Cable TRC 10220 TRC 10255

Never in Ocean

.221

.252

8850\%

2000

32 .

*Variation in breaking strength caused by termination technique. 
Conclusions. The combination of high tensile loads and much too small sheave diameters prompted accelerated cable failure. As expected, the higher the tension the smaller the number of cycles to failure. Of significance is the fact that even at relatively low tension levels, the cable fails within a few hundred cycles, a result which had been previously obtained in similar tests performed at the Preformed Line Products Co. Laboratories, (Reference 1). Obviously in all CTD applications the cable should not be passed over sma11 sheaves and the existing three wheels tension measuring devices should be removed and replaced by more suitable ones. 


\section{APPENDIX 2}

EVIDENCE OF PROBABLE CAUSE OF KINKING AND CONDUCTOR FAILURE IN CTD LOWERING CABLES (R/V KNORR CRUISE 非73 
APPENDIX 2

EVIDENCE OF PROBABLE CAUSE OF KINKING AND CONDUCTOR FAILURE IN CTD LOWERING CABLES (R/V KNORR Cruise 非73)

\section{Introduction}

Numerous CTD casts were taken during R/V KNORR Cruise 非3 in the rough sea states and extreme weather conditions prevalent in the waters south of Australia in October and November (Austral Spring) of 1978. Several instances of severe kinking, deformation and loss of signal in the lowering electromechanical cable occurred. Fortunately a11 cable damage was limited to within 10 meters of the instrument termination permitting cutting of the cable and reterminations to be made without significant reduction in usable cable length.

The electromechanical cable which experienced the damage was a 3-conductor double armor cable, type 3-H-305A, manufactured by Rochester. It had a strength of 7400 lbs, a .303 inch diameter, and its weight in sea water was $3801 \mathrm{bs} / \mathrm{km}$.

The instrument package attached at the lower end of the cable consisted of a NBSI CTD instrument and a General Oceanics 24 bottle rosette mounted in a protective cage. The immersed weight of the instrument package was $350 \mathrm{lbs}$, and its free fall terminal velocity approximately 150 meters/min $(8.2 \mathrm{ft} . \mathrm{sec})$.

Examination of samples of the damaged cable led to the conclusion that, in several instances, the lower end of the cable had slacked, formed a loop or loops and had been rapidly reloaded causing kinking, birdcaging and breaks in the conductors.

The most likely cause of such a sequence of events is the coupling of ship motion (roll, heave and pitch) through the head block to the lower end 
of the cable. If this cyclical movement is of sufficient magnitude then velocities of the wire would periodically exceed the terminal velocity of the instrument resulting in a rapidly alternating slacking and loading of the cable in the immediate vicinity of the termination.

To look for evidence of this condition, a typical pressure record, yielding the actual depth of the instrument every half second, was analyzed. Results of this analysis are hereafter presented.

\section{Pressure Record Analysis}

The pressure record of CTD station number 85 was selected for analysis. The weather prevailing at the time of the record was wind West force 6 , sea West state 4, swell West state 4. The ship log notes the vessel to be rolling "heavily".

The steps followed in the pressure record analysis included the following:

a) Selection of a representative set of pressure data points, measured every half second, over a 10 minute interval. During this interval the instrument was lowered from $5830 \mathrm{ft}$ (1778 meters) to $8150 \mathrm{ft}$ (2485m).

b) Conversion of pressure measurements to instrument depth: The depth difference between the beginning and the end of the 10 minute interval divided by the length of this time interval yielded the average cable payout rate (lowering speed). This was found to be $4.5 \mathrm{ft} / \mathrm{sec}$ or 83 meters/min. Dividing the depth difference between the beginning and the end of the half second time intervals by half a second, yielded the instrument instantaneous speed.

c) The instrument instantaneous speed can be thought of as made of two components. One is the steady state lowering speed which equals the winch payout rate. The other is the time varying deviation, introduced by wave action, from the constant lowering speed. The value of this deviation is simply the difference between the instantaneous (recorded) 
speed and the DC part of the signal. A typical graph of this deviation as a function of time is shown in Figure 11. One can note from this plot that the deviation is cyclic with a period of approximately 8.5 seconds. The plot also shows that the negative (downwards) peaks do not exceed a cut-off value of approximately $3.8 \mathrm{ft} / \mathrm{sec}$ (70 meters/min).

d) The frequency of occurrence of positive and negative peaks of speed deviation from the mean lowering speed was also established for speed increments of $0.328 \mathrm{ft} / \mathrm{sec}(0.1 \mathrm{~m} / \mathrm{sec})$. The resulting histogram is shown in Figure 12. One can note the presence of a cut-off of negative speeds at $3.8 \mathrm{ft} / \mathrm{sec}$. The dissimilarity in the shapes of the positive and negative parts of the histogram is also noteworthy. The positive part is symmetrical around the most probable value, whereas the negative is obviously skewed.

\section{Discussion}

The motion of a vessel in a sea-way tends to be periodic and displacements around the mean must be symmetrical. Therefore the vessel motion must impart a periodic and symmetrical upward and downward motion to the shipboard end of the cable. The degree of coupling between the motions of the upper and the lower ends of the cable is difficult to predict exactly. Figure 11 however clearly shows that a significant amount of surface motion is transmitted to the instrument.

Obviously when being hauled upwards the instrument moves at a speed equal to the cable speed. However when moving downwards, the instrument will remain coupled to the cable only as long as the cable speed does not exceed the instrument terminal velocity. If it does then the cable will over-run the instrument.

Had the instrument on station $\equiv_{185}$ never reached terminal velocity then the plots shown in Figures 11 and 12 would have been symmetrical around their horizontal axis, with the magnitude and distribution of positive and negative 


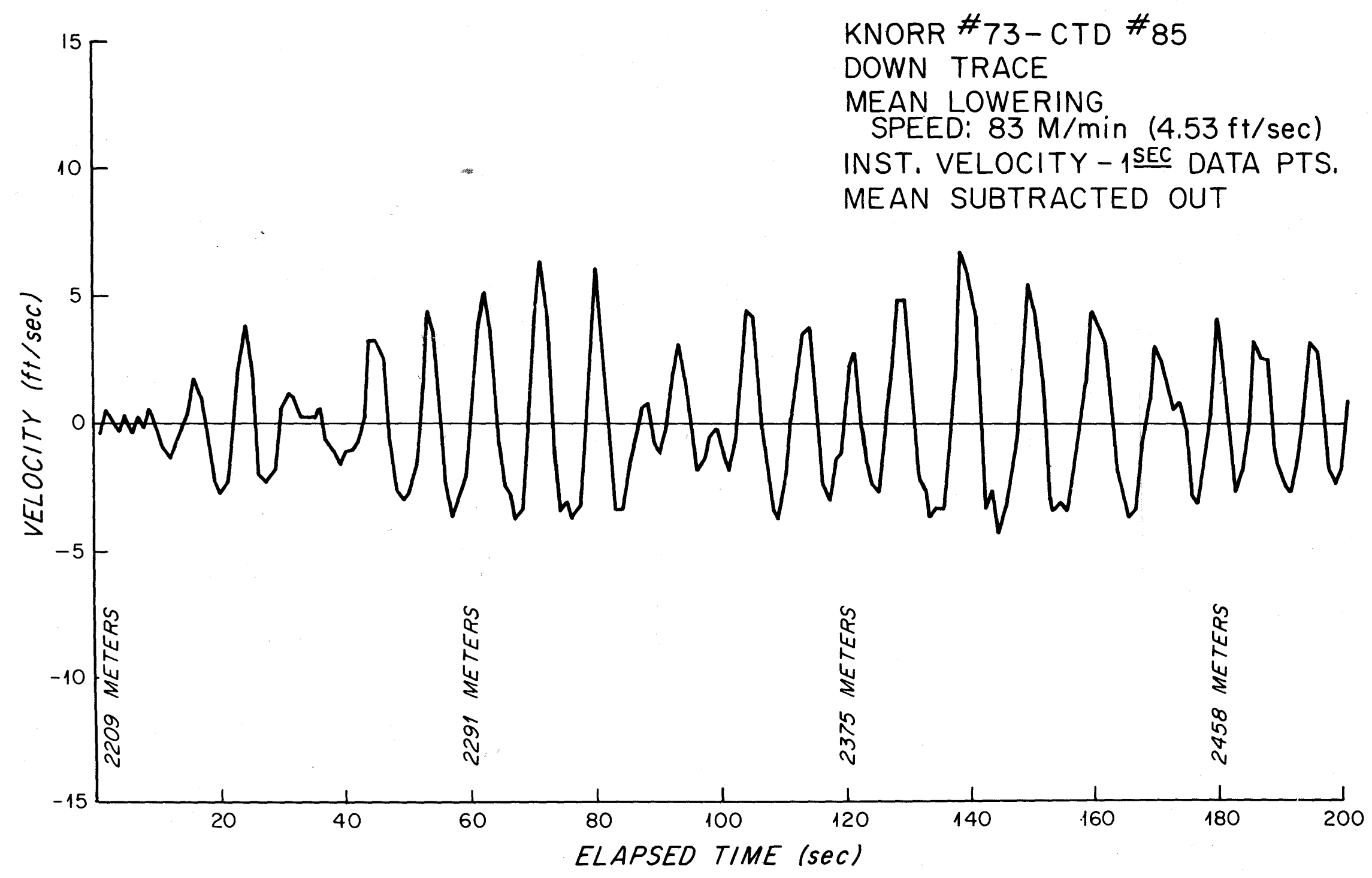




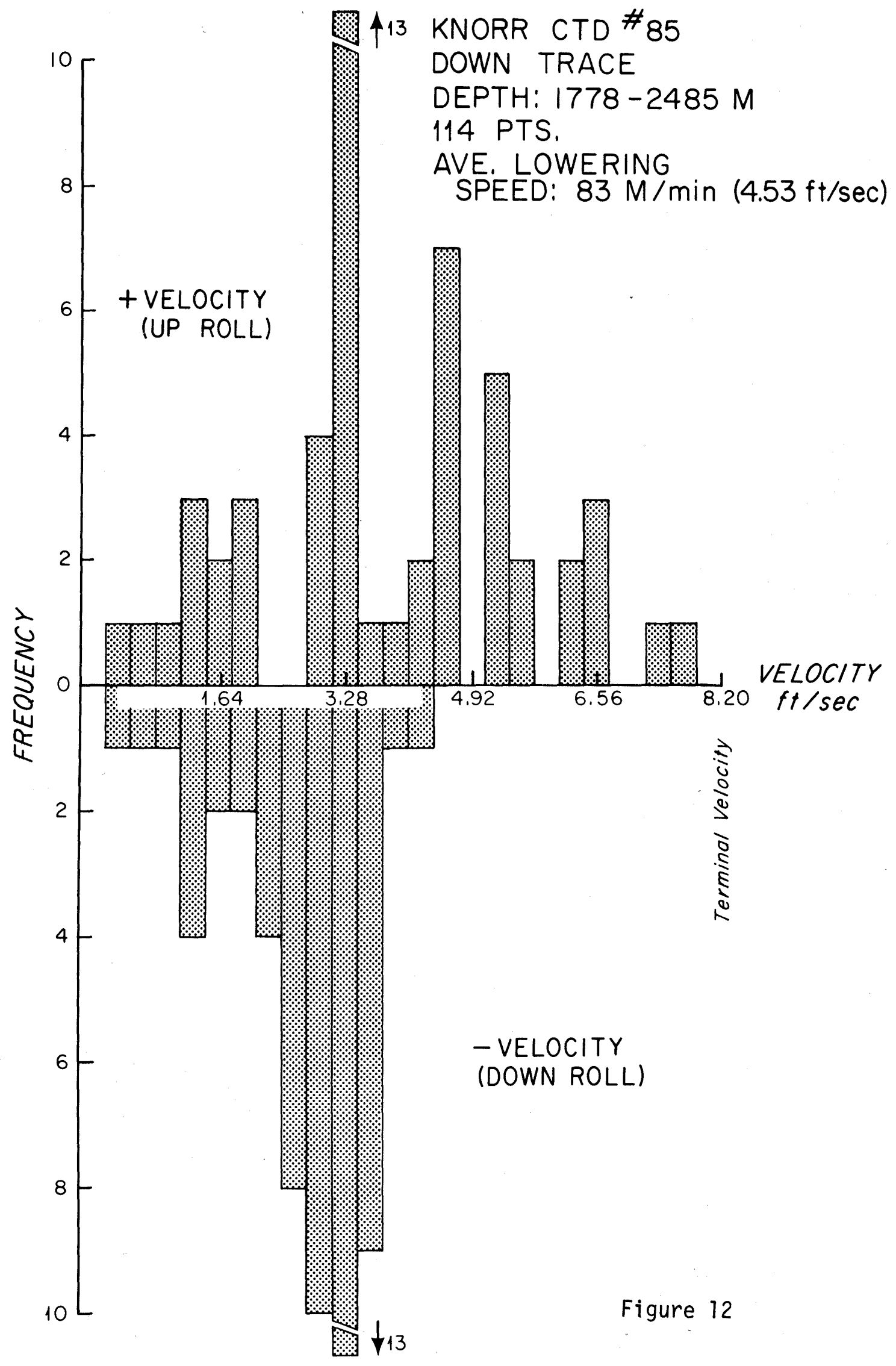


speed deviations being the same. However Figure 12 indicates that upwards deviations from the mean were as high as $8.0 \mathrm{ft} / \mathrm{sec}$, whereas the downwards never exceeded $3.8 \mathrm{ft} / \mathrm{sec}$.

If one again makes the reasonable assumption that the head sheave moves downwards at the same speed as upwards, then the maximum downwards speed $\left(\mathrm{V}_{\text {DOWN }}\right)$ experienced by the cable lower end would have been:

$$
\mathrm{V}_{\text {DOWN }}=(-4.5)+(-8.0)=(-12.5) \mathrm{ft} / \mathrm{sec}
$$

As previously mentioned the instantaneous speed of the instrument is the algebraic sum of the steady state and time varying components. Therefore the maximum downwards speed ( $W_{D O W N}$ ) experienced by the instrument is given by:

$$
\mathrm{W}_{\mathrm{DOWN}}=(-4.5)+(-3.8)=(-8.3) \mathrm{ft} . \mathrm{sec}
$$

which is in fair agreement with the known terminal velocity of the instrument. It thus appears that at least in one instance the cable was falling faster than the instrument by as much as $4.2 \mathrm{ft} / \mathrm{sec}$ ( 77 meters $/ \mathrm{min}$ ). Following this line of reasoning the histogram shown in Figure 12 indicates that during the length of the sample analyzed the cable downwards speed exceeded the instrument terminal velocity in $50 \%$ of the roll cycles considered. Conclusions

Conclusions to be drawn from this analysis are:

a) In several instances the instrument reached terminal velocity.

b) In several instances the cable speed exceeded the instrument speed thus allowing loops to form in the vicinity of the instrument termination.

c) As expected a significant amount of ship motion is transmitted to the lower end of the cable. Unfortunately this motion cannot be quantified in this case.

d) The lowering or payout rate of the cable was clearly excessive under the given sea conditions. 
e) Even with the winch secured the cable would have reached the instrument terminal velocity on some down rolls, showing that the sea conditions were too severe for taking a CTD station with this instrument package.

f) In order to take CTD casts in moderate to severe sea conditions the instrument terminal velocity must be increased. 
APPENDIX 3

E/M CABLE SPECIFICATIONS 


\section{APPENDIX 3}

\section{ELECTROMECHANICAL CABLE PROCUREMENT SPECIFICATIONS}

Buyer: Woods Hole Oceanographic Institution

Woods Hole, Massachusetts 02543

Attention

Te1: $617-548-1400$

Department

\section{Cable Application}

Winch

Drum Dia.

in. Sheave Dia.

in.

\section{Environment}

Temperature ${ }^{\circ} \mathrm{C} \min$. ${ }^{\circ} \mathrm{C} \max$.

Pressure Range

psi

Storage Conditions- At sea

On 1and

Required Mechanical Properties of Cable

Length ft. Continuous YES NO Number of lengths

Weight of payload 1bs. Cable Safety Factor

Material of strength members

Cable OD

in.

OD Tolerances +

Torque Balance degree/ft at

$\%$ RBS

Outer Jacket: Materia1

Thickness

Others 
Required Electrical Properties of Cable.

Number of conductors

Type

Material of conductors

Individual conductor capacity volts amperes

DC resistance ohms/1000 ft a ${ }^{\circ} \mathrm{C}$

Capacitance, to sea water muF / ft a $\mathrm{kHz}$

, to other conductors unF/ft $\mathbf{k H z}$

Insulation resistance

between

and

to be (ohms/1000 ft a DC Volts)

Cable attenuation

$\mathrm{db} / 1000 \mathrm{ft}$ a $\mathrm{kHz}$

others

$+$

Acceptance Testing. Tests shall be performed at the manufacturer's plant to ascertain that the mechanical and electrical properties of the cable are within specified requirements. Test results shall be documented and a copy sent to the buyer.

Special Testing: 
APPENDIX 4

E/M CABLE LIFE HISTORY DOCUMENTATION 


\section{APPENDIX 4 \\ E/M CABLE LIFE HISTORY DOCUMENTATION \\ SHIPBOARD ELECTROMECHANICAL (E/M) CABLE LOG}

1. Vesse1

Cruise No.

Leg No.

2. $\mathrm{E} / \mathrm{M} \mathrm{Cable}$

Cable Type:

Insta11.Date:

Diam: in. Strength:

Weight In Water $1 \mathrm{~b} / \mathrm{m}$

Installed Length:

3. E/M Cable Use

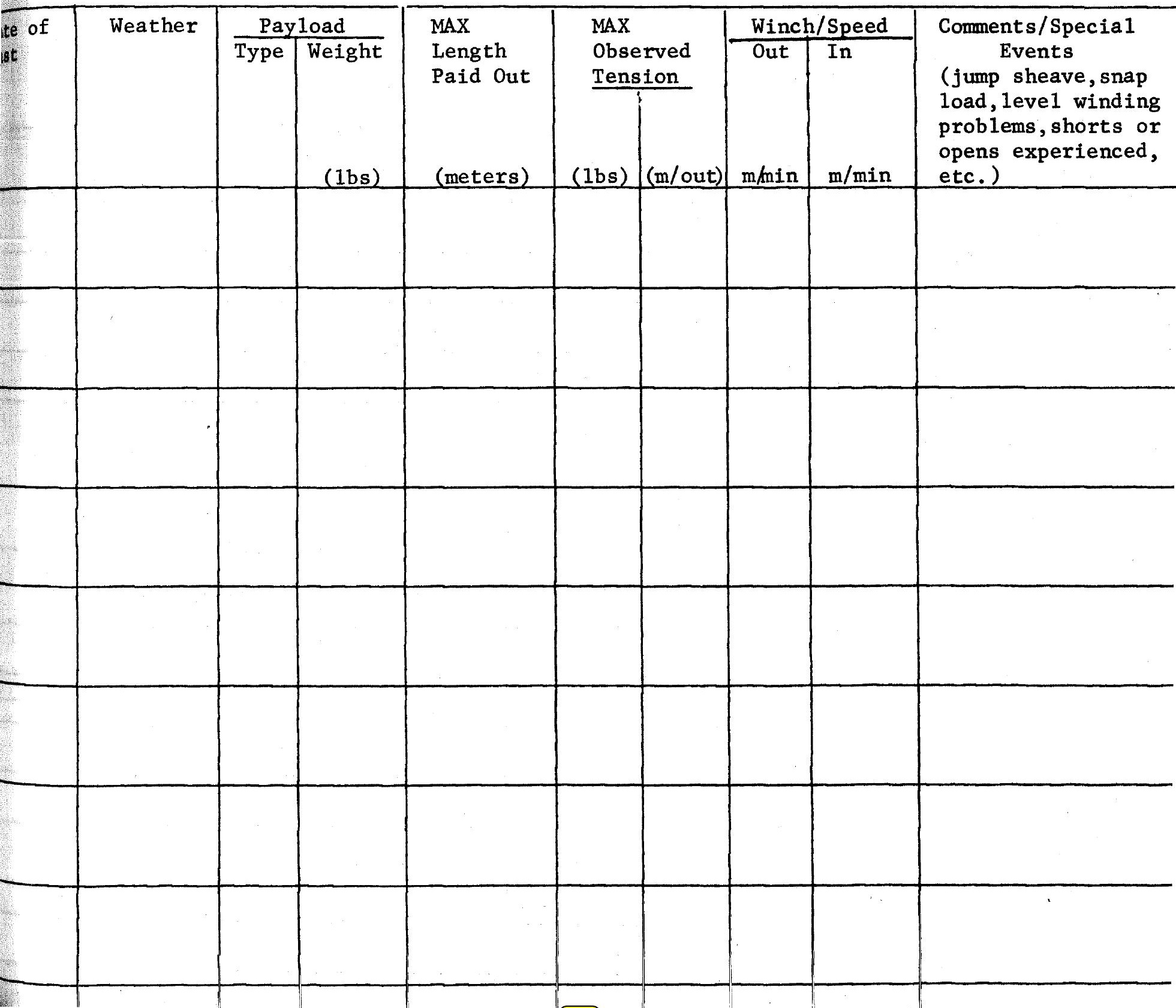




\section{$4.0 \mathrm{E} / \mathrm{M}$ Cable Maintenance \\ 4.1 Cable Inspection}

\begin{tabular}{l|l|l}
\hline Date & By & $\begin{array}{l}\text { Observations: Describe and locate cable damage such as: broken wires, kinks, } \\
\text { bird cage, heavy corrosion, etc..... }\end{array}$ \\
\hline & & \\
\hline & & \\
\hline
\end{tabular}

\subsection{Cable Lubrication}

\begin{tabular}{l|l|l|}
\hline Date & By & Procedure: (Rinse, type of lubricant, how applied). \\
\hline & & \\
\hline & & \\
\hline & & \\
\hline & & \\
\hline
\end{tabular}

\subsection{Cable Cutting}

\begin{tabular}{|c|c|c|c|c|c|}
\hline Date & By & Reason For & Length Cut Out & Remaining Length & Termination, Type \\
\hline & & & & & \\
\hline & & & & & \\
\hline & & & & & \\
\hline & & & & & \\
\hline
\end{tabular}




\section{ELECTROMECHANICAL (E/M) CABLE MAIN LOG (SHORE LOG)}

$1.0 \mathrm{E} / \mathrm{M}$ Cable Basic Data

Ordered by: W.H.O.I. P.O. 非

Date ordered: Date received:

Manufacturer:

Type:

\section{Construction}

Conductor:

Insulation:

Core:

Bedding:

Armor: Inner layer

Intermediate layer

Outer Layer

\section{Mechanical Specifications}

Outside diameter in $( \pm$ in)

Length when received ft

Weight in air $1 \mathrm{~b} / \mathrm{m} . \mathrm{ft}$

Weight in seawater $1 \mathrm{~b} / \mathrm{m} . \mathrm{ft}$

Ultimate Breaking Strength Ibs

Minimum sheave/drum diameter in

\section{Electrical Specifications}

Vo1tage rating

volts

Capacitance

F/ft

DC Conductor resistance

ohms/m.ft

DC Armor resistance ohms/m. ft 


\subsection{Acceptance Testing}

Diameter Measured

(Average of 2 measurements) $O D=$ in.

U1timate Breaking Strength (UBS)

(average of breaks)

Both ends Fixed

One End Fixed

$\mathrm{UBS}=$ $1 \mathrm{bs}$

$\mathrm{UBS}=$ 1bs

DC Conductor Resistance

Conductor 非

DC Resistance (ohms/m.ft)

Insulation DC Resistance

DC Volts applied:

Volts

Resistance Measured: $\mathrm{ohms} / \mathrm{m}$. ft 


\section{E/M Cable Main Log}

\subsection{Cable Life History}

\subsection{Cable Install Record}

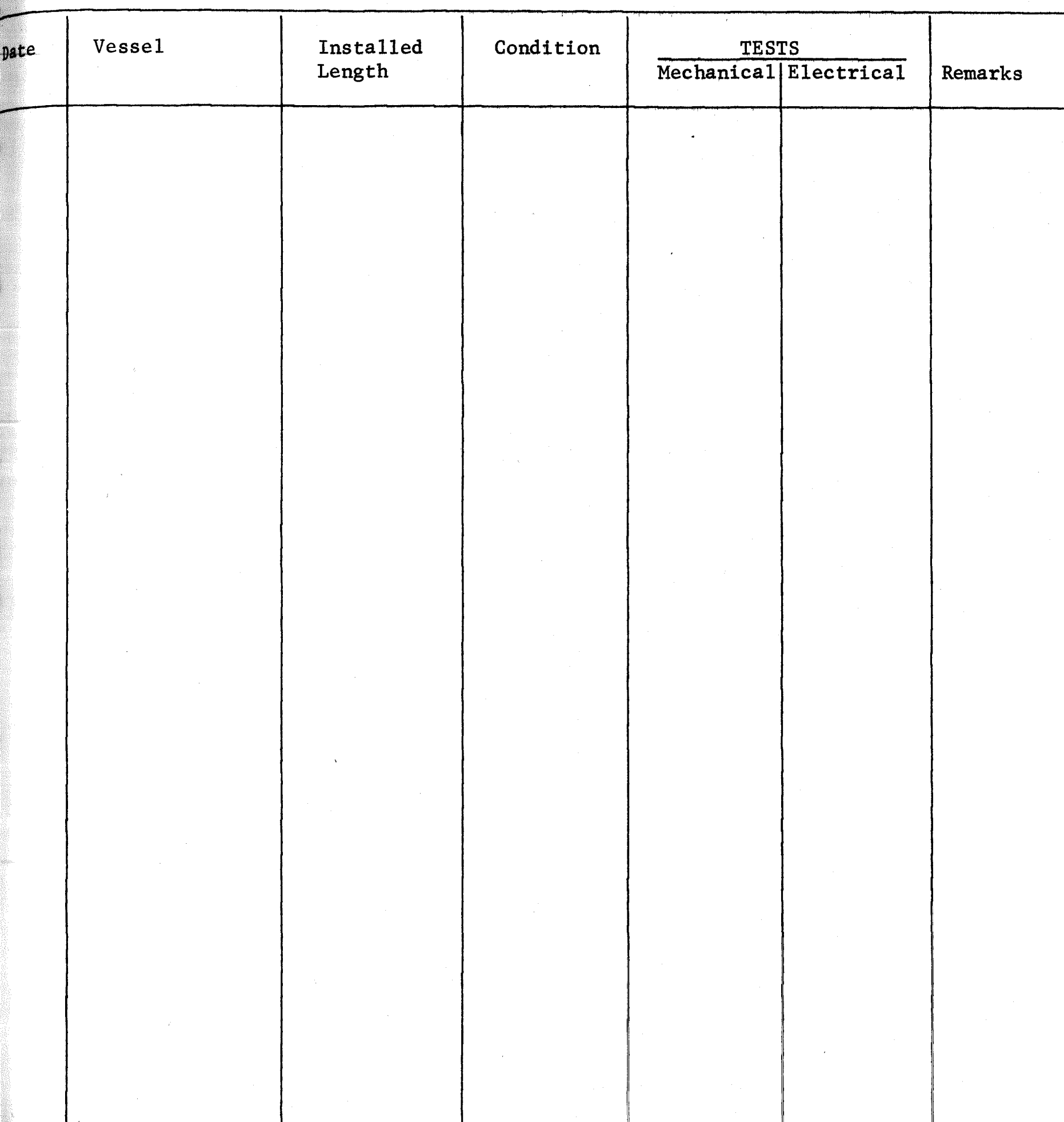


E/M Cable Main Log

3.2 Cable Remove/Store Record

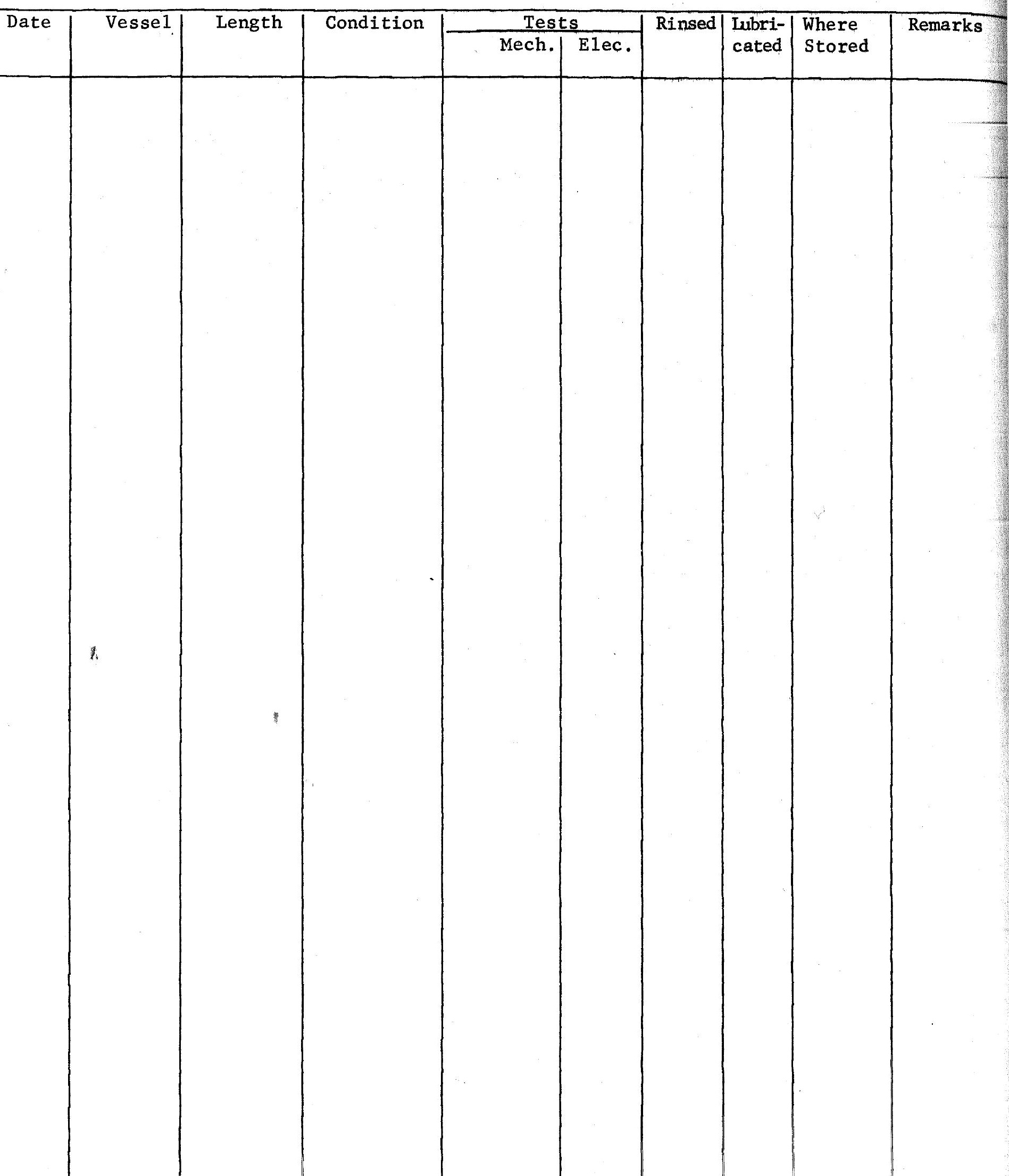




\section{E/M Cable Main Log}

4.0 Cable Maintenance Record

By Description of Maintenance Operation

(Inspection, lubrication, cutting, rewinding, Determination, etc....) 
APPENDIX 5

LUBRICANT DATA SHEET 
a testimonial:

"U.S. Steel feels that Pre-Lube 6 is an excellent product, and we are using it in our wire rope and other applications."

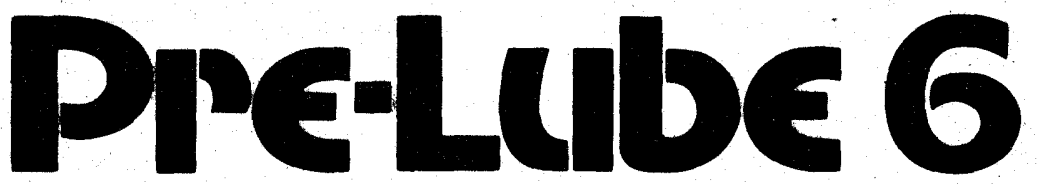

RUST PREVENTATIVE and LUBRICANT

APPLICATION DATA

REMOVABILITY

SPECIFICATIONS

OSHA COMPLIANCE
PL-6 may be applied by spraying, wiping, flow coating, dipping or brushing. For best corrosion resistance coated parts should be held for 8-16 hours for polymerization to occur before exposure to corrosive atmospheres.

PL-6 contains an oil base which is easily and thoroughly removed with any good petroleum or chlorinated solvent before welding, painting or other operation requiring clean, dry surfaces. Even after removal of the oil base, the special polymer in PL-6 will continue to provide protection against corrosion on most metal surfaces.

Solids content $100 \%$ active

Flash point (open cup test) $360^{\circ} \mathrm{F}$ Weight per gallon $7.75 \mathrm{lbs}$ Stability

Min. pour point

Coverage

Diluting agents Removal agent

Excellent $-20^{\circ} \mathrm{F}$ Over 1200 sq. ft./gal. Petroleum oil or solvent

Pre-Lube 6 is not considered a hazardous material by currentlyaccepted OSHA definition. (29 CFR 1915.2 of the Longshoremen's and Harbor Workers' Act which has been adopted as a Standard under the Occupational Safety and Health Act of 1970.) OSHA form 20, Material Data sheet, available on request.

For trial order or additional information:

\section{DAS Sales Corporation}

556 Commercial Avenue $=$ Garden City, N.Y. 11530 (516) 222-0154 New York City: (212) 343-1123

PACKAGING Pre-Lube 6 is available in non-flourinated aerosol dispensers, 5-galIon pails, 30-gallon and 55-gallon drums. 


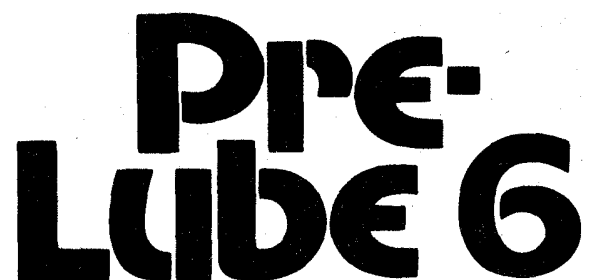

\section{A Rust Preventative Polymer that really works}

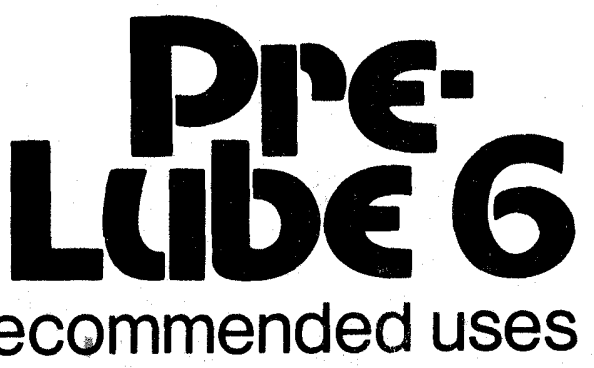

Causative factors of rust and corrosion on metal parts. products and machinery throughout industry are numerous and varied. Given a wide specirum

of causes, ordinary commercial inhibitors will deliver mixed results at best. By comparison, only Pre-Lube 6 is consistently more effective even under the most difficult circumstances.
In simple terms, Pre-Lube 6 for industrial metal protection contains a special rust-inhibiting polymer in a penetrating oil base. On metal surfaces of all kinds, it removes moisture and protects against salt mist and rain, acid fumes and other corrosive atmospheres.

As independent tests prove, it can provide unfailing protection indefinitely, depending on actual conditions of use.

PRE-LUBE 6 protects metal surfaces against salt water, acid fumes and other corrosive atmospheres.

PRE-LUBE 6 penetrates wire rope providing interstrand lubricity, protection against corrosion and preventing mildewing of hemp cores.

PRE-LUBE 6 protects galvanized steel against red rust and staining.

PRE-LUBE 6 protects aluminum against oxidation.

PRE-LUBE 6 is the ideal substitute for asphalt and other heavy petroleum coatings. PL-6 is not tacky, will not crack and allows visual inspection of coated parts.

PRE-LUBE 6 protects and lubricates moving machinery - control cables, winches, clutches, bearings and the like.

PRE-LUBE 6 penetrates rusted parts to free them and inhibits further corrosion. 


\section{Major Steel Corporation's Test*}

Specifically, one of the nation's largest steel producers needed to prevent white rust corrosion on galvanized steel wire rope which was stored outdoors for 3-month periods. Four protective coatings, including those in widest use, were laboratory-tested for effectiveness. Here, verbatim, is the senior engineer's summary of test results:

"Small strand samples were dipped into the various protective coatings and excess material allowed to drain off. The treated strands were exposed in a humidity cabinet at $100 \% \mathrm{RH}$ and $120^{\circ} \mathrm{F}$, and examined periodically for indications of attack on the zinc coating. As can be seen from the table of results, the performance of one product-Pre-Lube 6-far exceeded all other materials tested."

\section{HUMIDITY TEST RESULTS}

TEMPORARY PROTECTIVE COATINGS

Condition of Galvanized Surface

\begin{tabular}{|c|c|c|c|c|c|}
\hline 1 day & $N^{* *}$ & NA & NA & $\begin{array}{l}\text { Light white } \\
\text { rust }\end{array}$ & $\begin{array}{l}\text { Heavy white } \\
\text { rust }\end{array}$ \\
\hline 3 days & NA & NA & NA & $\begin{array}{l}\text { Moderate } \\
\text { white rust }\end{array}$ & $\begin{array}{c}\text { Heavy white } \\
\text { rust }\end{array}$ \\
\hline 7 days & NA & NA & NA & $\begin{array}{c}\text { Heavy white } \\
\text { rust }\end{array}$ & $\begin{array}{l}\text { Heavy white } \\
\text { rust-few red } \\
\text { rust specks }\end{array}$ \\
\hline 35 days & NA & $\begin{array}{l}\text { Moderate } \\
\text { white rust }\end{array}$ & $\begin{array}{l}\text { Very light } \\
\text { white rust }\end{array}$ & $\begin{array}{l}\text { Heavy white } \\
\text { rust }\end{array}$ & $\begin{array}{l}\text { Heavy white } \\
\text { rust-few red } \\
\text { rust specks }\end{array}$ \\
\hline 3 months & NA & $\begin{array}{l}\text { Heavy white } \\
\text { rust-trace } \\
\text { of red rust }\end{array}$ & $\begin{array}{l}\text { Moderate } \\
\text { white rust }\end{array}$ & $\begin{array}{l}\text { Heavy white } \\
\text { rust-trace } \\
\text { of red rust }\end{array}$ & $\begin{array}{l}\text { Heavy white } \\
\text { rust-few red } \\
\text { rust specks }\end{array}$ \\
\hline 4 months & $\mathbf{N A}$ & $\begin{array}{l}\text { Heavy white } \\
\text { rust-trace } \\
\text { of red rust }\end{array}$ & $\begin{array}{l}\text { Moderate } \\
\text { white rust }\end{array}$ & $\begin{array}{c}\text { Heavy white } \\
\text { rust-trace } \\
\text { of red rust }\end{array}$ & $\begin{array}{l}\text { Heavy white } \\
\text { rust-few red } \\
\text { rust specks } \\
\end{array}$ \\
\hline
\end{tabular}

- Name on request. See customer list below.

- No attack - no white rust or red rust or stain.

\section{Pre-Lube 6: Widely Used in}

\section{Military and Commercial Applications}

Though relatively unpublicized until now, Pre-Lube 6 has been in regular use for several years by some of the Nation's most demanding consumers. Among them:

\section{American Bridge \\ Div., U.S.Steel \\ Bethlehem Steel \\ Deep Sea Ventures \\ Fairchild Republic Aviation \\ Farrel Lines \\ Lamont Geological Observatory \\ LTV}

Moran Towing

\section{Oregon State - \\ Dept. of \\ Oceanography}

Paulsen -

Webber Cordage

Subsea International

\section{U.S. Coast Guard}

\section{U.S. Department of Commerce - Sport Fisheries}

\section{U.S. Navy}

Western Electric

\section{The $5 \%$ Salt Fog ASTM Test}

Subjected to a standardized ASTM $5 \%$ salt fog test. Pre-Lube 6 proves totally effective against red rust on rolled steel. In this accelerated laboratory procedure, two sets of steel panels coated with inhibitors to be comparison-tested are suspended in a weather chamber. An aqueous fog containing $5 \%$ salt by weight is introduced and maintained under controlled heat and pressure. Development of rust is visually appraised on one set of panels after 24 hours and on the second set of panels after 48 hours.

In the typical reproducible result shown below, panels coated with Pre-Lube 6 develop no traces of rust whatever. By contrast, those treated with WD-40 and 20 -weight machine oil develop heavy accumulations.

\section{4-HOUR EXPOSURE}

Pre-Lube 6

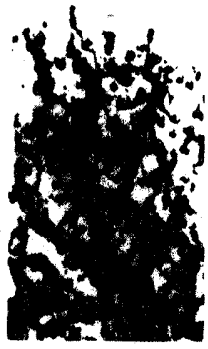
WD-40

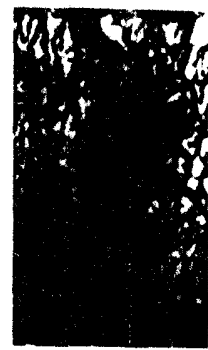

20W Oil

48-HOUR EXPOSURE

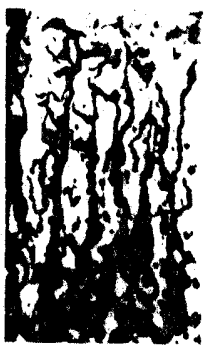

WD -40

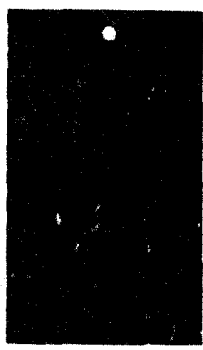

20W Oil:

Pre-Lube 6

\section{Superior Coating Makes the Differerice}

The critical difference between Pre-Lube 6 and competitive products is simply this:

Held for 8 hours or more before exposure, metal parts and surfaces develop a protective coating which lasts indefinitely. Treated surfaces continue to be protected even after the oily base is cleaned off with solvent. Without effecting painting, welding or other operations, the invisible shield remains.

A simple demonstration of the effect is illustrated below. In this instance, mild steel panels were suspended in a weather chamber at $98 \% \mathrm{RH}$ and $70^{\circ} \mathrm{F}$ (room temperature). One was untreated. The other was pre-treated with Pre-Lube 6 for eight hours, then cleaned with a chlorinated solvent before testing. Both were sprayed once with water mid-way in the 48-hour test period. As can be clearly seen, the untreated panel developed heavy staining. The PreLube 6 panel remained totally unaffected.

STAINING TEST 48 Hours at $98 \% \mathrm{RH}$ and $70^{\circ} \mathrm{F}$ Sprayed After First 24 Hours with Water

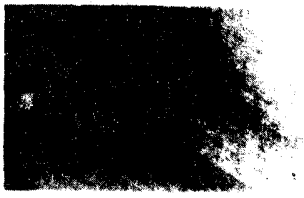

Pre-Lube 6 Panel

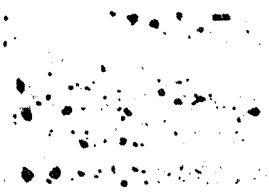

Untreated Panel 
APPENDIX 6

WINCH DOCUMENTATION 
APPENDIX 6

CTD (ACOUSTIC) WINCH MAINTENANCE LOG

WINCH TYPE:

ESSEL:

SERIAL NUMBER:

\begin{tabular}{|l|l|l|}
\hline DATE & BY & $\begin{array}{l}\text { DESCRIPTION OF MAINTENANCE OPERATION } \\
\text { (Oiling, Greasing, Changing Parts, Calibration } \\
\text { of Meters, etc...) }\end{array}$ \\
\hline
\end{tabular}


APPENDIX 7

COMPUTATION OF PEAK TENSION IN CTD CABLES AT THE HEAD SHEAVE OF A SHIP UNDERGOING BOTH HEAVE AND ROLL 


\section{APPENDIX 7}

COMPUTATION OF PEAK TENSION IN CTD CABLES AT THE HEAD SHEAVE

OF A SHIP UNDERGOING BOTH HEAVE AND ROLL

\section{Assumptions}

1. Tension on the cable is due to the sum of static and dynamic forces. The static components of tension are simply the immersed weight of the cable and of the instrument. The dynamic forces are the result of drag and inertia as based on Morison's formulas.

2. Elasticity of the cable is not considered. This restricts the validity of the model particularly if resonant conditions prevail. Yet results found using this simple approach are representative of the high tension values observed at sea under adverse conditions.

3. Cable and instrument package move vertica11y.

\section{General Tension Equation}

Based on the assumptions above, the equation for the tension in the cable can be expressed as follows:

$$
T=T_{S}+T_{D}
$$

where $T=$ total tension in the cable

$$
\begin{aligned}
& T_{s}=\text { static component of tension } \\
& T_{D}=\text { dynamic component of tension }
\end{aligned}
$$

The static component of tension, which would equal the total tension in calm seas, is of the following form:

$$
T_{5}=W L+W_{I}
$$

where $W=$ immersed weight per foot of the cable

$$
L=1 \text { ength of cable }
$$

$W_{I}=$ immersed weight of the instrument 
The tension in the cable due to dynamic effects is the vector sum of drag and inertia forces. The drag force is proportional to the square of the velocity while the inertia force is proportional to the acceleration. Since the cable has been assumed to move vertically, the vertical velocity of the head sheave is used to calculate both velocity and acceleration of the cable-CTD package. The dynamic tension equation can therefore be expressed as:

$$
T_{D}=D_{C}+D_{I}+I_{C}+I_{I}
$$

where

$$
\begin{aligned}
& D_{C}=\text { drag force on the cable } \\
& D_{I}=\text { drag force on the instrument } \\
& I_{C}=\text { inertia force on the cable } \\
& I_{I}=\text { inertia force on the instrument }
\end{aligned}
$$

The expression of the drag force on the cable is:

$$
D_{C}=\frac{1}{2} \rho C_{D C} \pi d L \mid V / V
$$

where

$$
\rho=\text { density of seawater }
$$

$C_{D C}=1$ longitudinal drag coefficient of the cable

$$
d=\text { diameter of the cable }
$$

$V$ = vertical velocity of the cable

The drag force on the instrument can similarly be written as:

$$
D_{I}=\frac{1}{2} \rho\left(C_{D} A\right)_{I} / V / V
$$

where $\left(C_{D} A\right)_{I}=$ drag constant of instrument package The inertia force equations are of the following form:

$$
I_{c}=m_{v c} \alpha
$$

where

$$
\begin{aligned}
M_{v C} & =\text { virtual mass of the cable } \\
\alpha_{L} & =\text { vertical acceleration of the cable }
\end{aligned}
$$

and 


$$
I_{I}=m_{V I} a
$$

where

$$
M_{V I}=\text { virtual mass of the instrument }
$$

The expression for the dynamic tension can therefore be written as:

$$
T_{D}=\frac{1}{2} \rho C_{D C} \pi d L / v / v+\frac{1}{2} \rho\left(C_{D} A\right)_{I} / v / v+m_{V C} a+M_{V I} a
$$

or

$$
T_{D}=\frac{1}{2} \rho\left(C_{D C} \pi d L+\left(C_{D} A\right)_{I}\right) / V / V+\left(M_{V_{C}}+M_{V I}\right) a
$$

The general tension equation can then be written as:

$$
\begin{aligned}
T= & W L+W_{I}+\frac{1}{2} \rho\left(c_{D C} \pi d L+\left(C_{D} A\right) I\right) / V / V \\
& +\left(M V_{C}+M_{V I}\right) a
\end{aligned}
$$

III. Equations of Motion of the Head Sheave

1. Assumptions

a. Vertical motion of the sheave is caused by heave and roll only. Pitch is neglected as winch is assumed to be amidship, or close by.

b. Period of heave and period of roll are equal to make the computations simpler and so that the resultant motions are cumulative in effect and would approximate the worst case for a given sea state.

2. Equations of Motion due to Ro11

The equations of motion for the vertical velocity of the sheave due to roll are based on Figure 13 . 


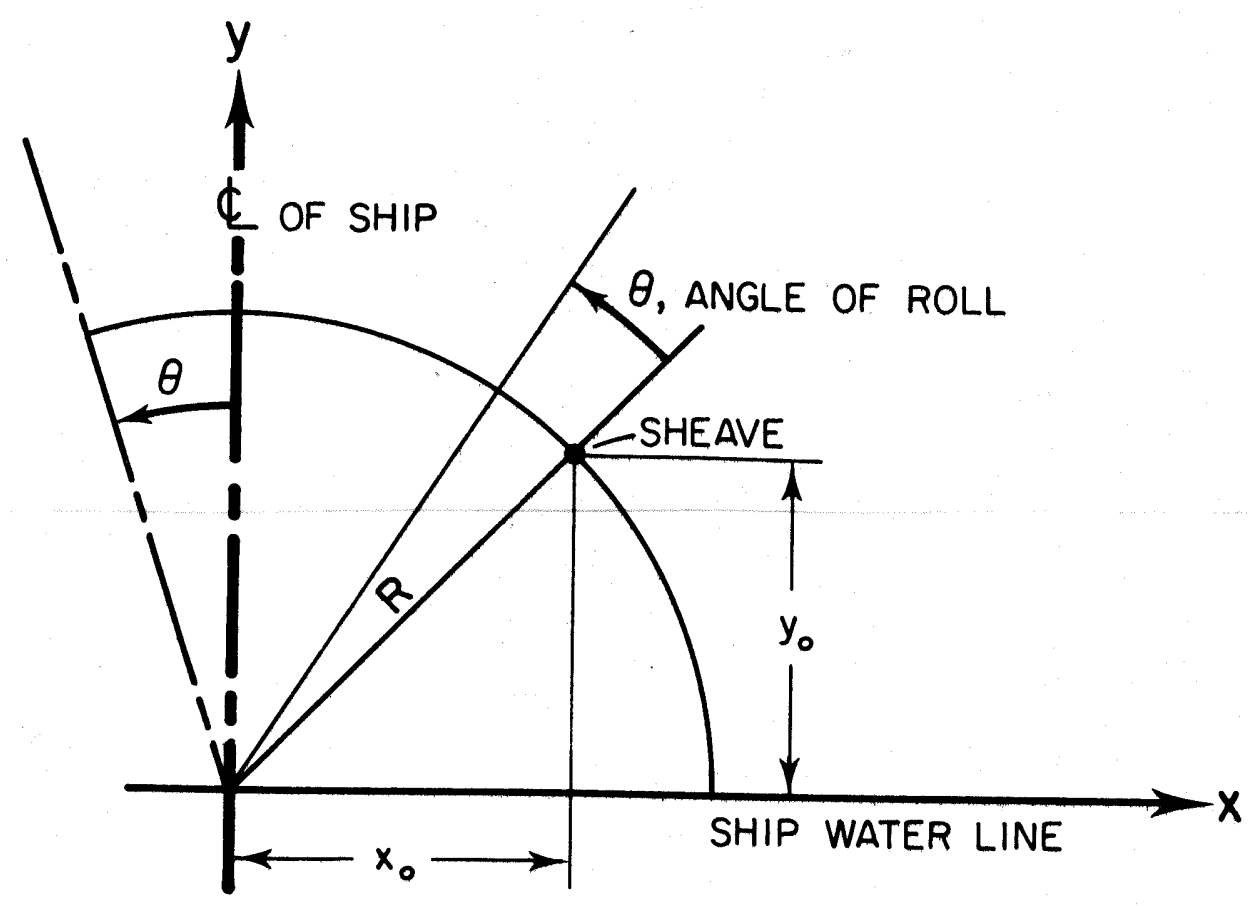

Figure 13. Geometry of Sheave Motion

where $X_{0}=$ horizontal distance from ship centerline to sheave $Y_{0}=$ vertical distance from ship waterline to sheave $R=\left(x_{0}^{2}+y_{0}^{2}\right)^{1 / 2}$

$\beta=\tan ^{-1}\left(y_{0} / x_{0}\right)$

$\Theta=$ angle of roll

1) For any point $(x, y)$ on the arc travelled by the sheave, the following relationship holds:

$$
\begin{aligned}
& y=R \sin (\beta+\theta) \\
& \text { where } \theta=\theta_{0} \sin \frac{2 \pi}{T} \epsilon \\
& \text { and } T=\text { period of roll } \\
& t=\text { time }
\end{aligned}
$$

Therefore, the expression of the vertical location of the sheave is:

$$
y=R \sin \left(\beta+\theta_{0} \sin \frac{2 n}{T} t\right)
$$


$\mathrm{Pg} .5$ of 15

Taking the time derivative of Equation 10 yield the vertical velocity of the sheave:

$\dot{y}=R \cos \left(\beta+\theta_{0} \sin \frac{2 \pi}{T} t\right)\left(\frac{2 \pi}{T} \theta_{0} \cos \frac{2 \pi}{T} t\right)$

which simplifies to:

$$
\dot{y}=\frac{2 \pi}{T} R \theta_{0} \cos \left(\frac{2 \pi t}{T} t\right) \cos \left(\beta+\theta_{0} \sin \left(\frac{2 \pi t}{T}\right)\right.
$$

The vertical acceleration of the sheave can similarly be found by the differentiation of Equation 11:

$$
\begin{aligned}
\ddot{y}=\frac{2 \pi}{T} R \theta_{0} & \left\{-\frac{2 \pi}{T} \sin \left(\frac{2 \pi t}{T}\right) \cos \left(\beta+\theta_{0} \sin \left(\frac{2 \pi t}{T}\right)\right)\right. \\
& \left.\left.-\cos \left(\frac{2 \pi t}{T}\right) \sin \left(\beta_{+} \theta_{0} \sin \left(\frac{2 \pi t}{T}\right)\right)\left(\frac{2 \pi}{T} \theta_{0} \cos \frac{2 \pi t}{T}\right)\right)\right\}
\end{aligned}
$$

which simplifies to:

$$
\begin{aligned}
& \ddot{y}=-\left(\frac{2 \pi}{T}\right)^{2} R \theta_{0}\left\{\theta_{0} \cos ^{2}\left(\frac{2 \pi t}{T}\right) \sin \left(\beta+\theta_{0} \sin \left(\frac{2 \pi}{T} t\right)\right)\right. \\
& \left.+\sin \left(\frac{2 \pi t}{T}\right) \cos \left(\beta+\theta_{0} \sin \left(\frac{2 \pi}{T} t\right)\right)\right\}^{T}
\end{aligned}
$$

3. Equations of Motion due to Heave

Heave motion is represented by a simple sine wave of the following form:

$$
\eta=A \sin \left(\frac{2 n}{T}\right) t
$$

where.

$$
\begin{aligned}
& Z=\text { sheave vertical displacement due to heave } \\
& A=\text { amplitude of heave motion } \\
& T=\text { period of heave motion }
\end{aligned}
$$

The sheave location can therefore be expressed as:

$$
y=A \sin \left(\frac{2 \pi}{T} t\right)
$$


$\mathrm{Pg} .6$ of 15

From this equation:

$$
\begin{aligned}
& \dot{y}=\frac{2 \pi}{T} A \cos \left(\frac{2 \pi t}{T}\right) \\
& \ddot{y}=-\left(\frac{2 \pi}{T}\right)^{2} A \sin \left(\frac{2 \pi t}{T}\right)
\end{aligned}
$$

4. Equations of Motion due to Roll and Heave

As previously stated, the period of roll is assumed to equal the period of heave. Hence, the equations of vertical motion of the sheave are:

$$
\begin{aligned}
& y=R \sin \left(\beta+\theta_{0} \sin \left(\frac{2 \pi t}{T}\right)\right)+A \sin \left(\frac{2 \pi t}{T}\right) \\
& \dot{y}=\frac{2 \pi}{T} R \theta_{0} \cos \left(\frac{2 \pi t}{T}\right) \cos \left(\beta+\theta_{0} \sin \left(\frac{2 \pi t}{T}\right)\right)+\frac{2 \pi}{T} A \cos \left(\frac{2 \pi t}{T}\right)
\end{aligned}
$$

which simplifies to:

$$
\dot{y}=\frac{2 \pi}{T} \cos \left(\frac{R \pi}{T} t\right)\left\{R \theta_{0} \cos \left(\beta+\theta_{0} \sin \left(\frac{2 \pi t}{T}\right)\right)+A\right\}
$$

and:

$$
\begin{aligned}
\ddot{y}= & -\left(\frac{2 \pi}{T}\right)^{2} R \theta_{0}\left\{\theta_{0} \cos ^{2}\left(\frac{2 m}{T}\right) \sin \left(\beta+\theta_{0} \sin \left(\frac{2 \pi t}{T}\right)\right)\right. \\
& \left.+\sin \left(\frac{2 \pi t}{T}\right) \cos \left(\beta+\theta_{0} \sin \left(\frac{2 m}{T} t\right)\right)\right\}-\left(\frac{2 \pi}{T}\right)^{2} A \sin \left(\frac{2 \pi t}{T}\right)
\end{aligned}
$$

which becomes:

$$
\begin{aligned}
\ddot{y}= & -\left(\frac{2 \pi}{T}\right)^{2}\left\{A \sin \left(\frac{2 \pi t}{T}\right)+R \theta_{0}\left[\theta _ { 0 } \operatorname { c o s } ^ { 2 } ( \frac { 2 \pi t } { T } ) \operatorname { s i n } \left(\beta+\theta_{0} \sin \left(\frac{2 n t}{T}\right)\right.\right.\right. \\
& \left.\left.+\sin \left(\frac{2 \pi t}{T}\right) \cos \left(\beta+\theta_{0} \sin \left(\frac{2 \pi t}{T}\right)\right)\right]\right\}
\end{aligned}
$$

Graphs of vertical velocity, vertical acceleration, tension due to drag, tension due to inertia, and total dynamic tension for a $3 \mathrm{ft}$ amplitude of heave, $15^{\circ}$ of roll, and a period of 8 seconds are shown in Figures 14 and 15 . 

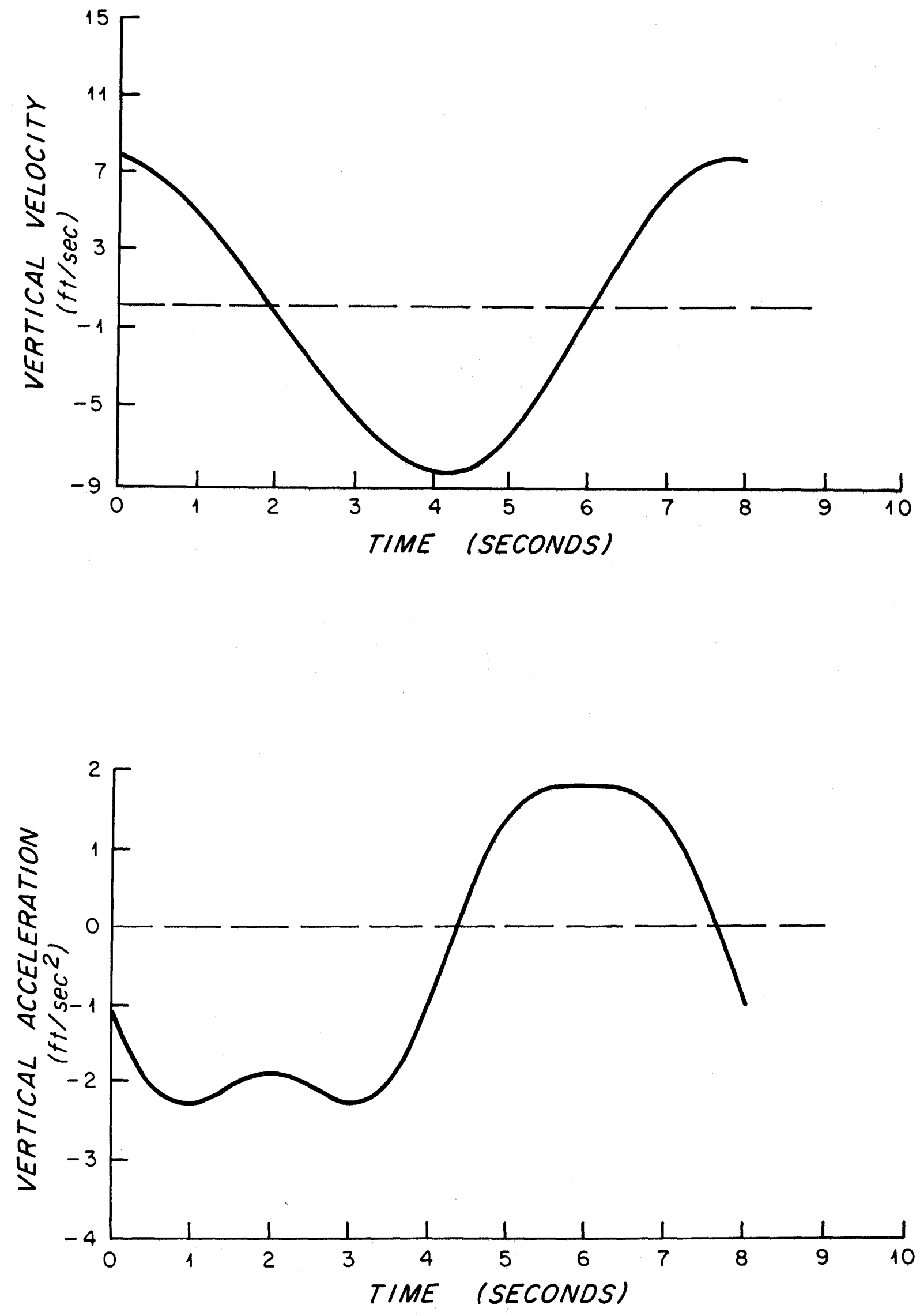

Figure 14 

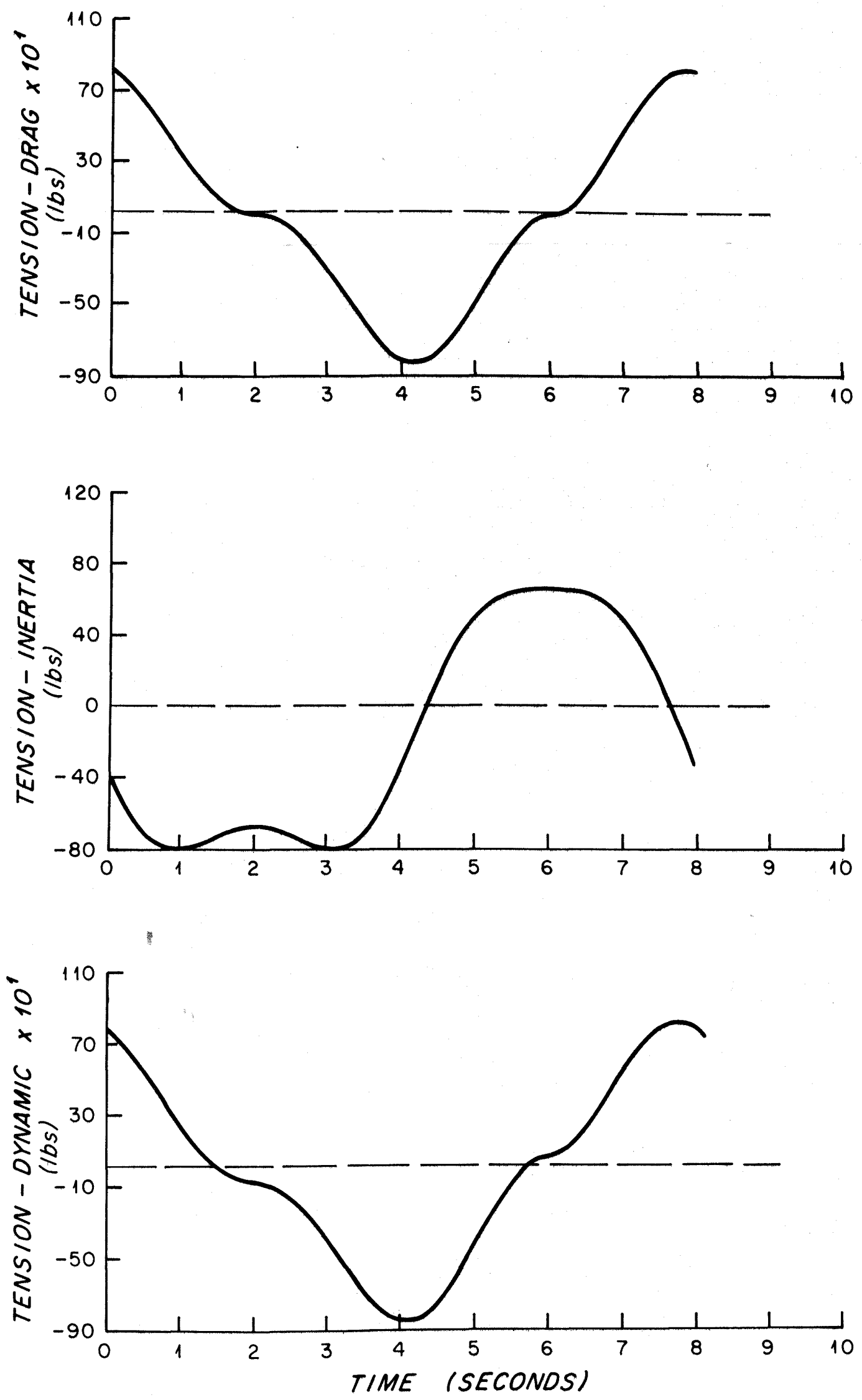


\section{Computation of Peak Tension at the Head Sheave}

Substitution of the expressions of vertical velocity (Eq.17) and acceleration (Eq.18) into the dynamic tension Equation (8) yields:

$$
\begin{aligned}
T_{D}= & \frac{1}{2} \rho\left(C_{D C} \pi d L+\left(C_{D} A\right)_{I}\right)\left(\frac { 2 \pi } { T } \operatorname { c o s } ( \frac { 2 \pi t } { T } ) \left[R \theta_{0} \cos \left(\beta+\theta_{0} \sin \left(\frac{2 \pi t}{T}\right)\right)\right.\right. \\
& +A] \int\left(\frac{2 \pi}{T} \cos \left(\frac{2 \pi t}{T}\right)\left[R \theta_{0} \cos \left(\beta+\theta_{0} \sin \left(\frac{2 \pi t}{T}\right)\right)+A\right]\right) \\
- & \left(\min V_{c}+m_{v_{i}}\right)\left\{\left(\frac{2 \pi}{T}\right)^{2} / A \sin \left(\frac{2 \pi t}{T}\right)+R \theta_{0}\left(\theta_{0} \cos ^{2}\left(\frac{2 \pi t}{T}\right) x\right.\right. \\
& \left.\left.\sin \left(\beta+\theta_{0} \sin \left(\frac{2 \pi t}{T}\right)\right)+\sin \left(\frac{2 \pi t}{T}\right) \cos \left(\beta+\theta_{0} \sin \left(\frac{2 \pi t}{T}\right)\right)\right]\right\}
\end{aligned}
$$

To determine the peak tension in the cable, the maximum dynamic tension must be found. This is done with the help of a computer program named CTDTEN. The program first computes the value of the dynamic tension (as given by Equation (19)) at discrete time intervals. It then uses an iterative routine, based on the Fibonacci technique, to find the time corresponding to the maximum tension value computed. Next the program computes the sheave velocity at that particular time, using Equation (17), adds to this value the hauling speed and calculates the tension due to drag. It also computes the acceleration at the time of $\mathrm{T}_{\mathrm{D}} \max$, and the corresponding component of tension due to inertia. It finally adds the static tension for the length of cable considered to find the value of the maximum tension at the sheave. A detailed description of this program follows hereafter.

V. A Computer Program to find the Maximum Tension in CTD Cables at the Head Sheave of a Ship Undergoing Both Heave and Ro11 
NAME :

TYPE:

PURPOSE :

MACHINE :

\section{SOURCE IANGUAGE: Xerox Extended FORTRAN IV}

PROGRAM CATEGORY: Numerical Mode1

DESCRIPTION: in CID cable at the head sheave while the cable is being hauled in by a ship undergoing both heave and roll. The tension in the cable for this case can be broken into two parts, a static component and a dynamic one. The static tension is simply the weight of the cable plus the weight of the instrument. The dynamic tension, however, is a result of the combined effects of drag, which is proportional to the square of the velocity, and inertia, which is proportional to the acceleration. The program first computes the dynamic tension due to head sheave motion alone (winch secured). It then finds the time at which maximum tension occurs and computes the sheave speed and h acceleration at that time. The haul in speed is then added to the dynamic vertical velocfty to compute the tension due to drag and the acceleration is multiplied by the virtual mass of the system to find the tension due to inertia. The dynamic components of tension are then added to the static ones and the maximum tension on the cable at this point is outputted.

The program has been written to be run on-line or as a batch job, but the primary method of use is assumed to be on-line. The user must supply parameters defining the cable characteristics, the instrument characteristics, the location of the sheave, the sea state, the haul in speeds and the tolerance. The user supplied parameters used in the computations are: 
SLENTH total length of cable to be hauled in, meters

SLINC increment of length for each calculation, meters

WT1000 cable dry weight per $1000 \mathrm{ft}, 1 \mathrm{~b} / 1000 \mathrm{ft}$

DIAM diameter of the cable, inches

CDLINE longitudinal drag coefficient of the cable

CBSTR rated breaking strength of the cable, $1 \mathrm{bs}$

WTINST immersed weight of the instrument, lbs

CDAI drag constant of the instrument, feet ${ }^{2}$

Note: The drag constant is here defined as the product of the drag coefficient by the area normal to the flow.

VMINST virtual mass of the instrument, slugs

XSHIV horizontal distance from waterline of ship to sheave, feet

YSHIV vertical distance from waterline of ship to sheave, feet

PERIOD period of oscillation of both heave and roll, seconds

HEVAMP amplitude of heave, feet

ANGROL angle of roll, degrees

$\mathrm{N}$ number of haul in speeds to be inputted, up to five maximum

PAYRAT (N) haul in speeds, meters/min, up to 5 and equal to $\mathrm{N}$

TOL tolerance or increment length to be used to determine the time at which maximum dynamic tension occurs, seconds

When all the parameters have been inputted, the program types the input parameters in a table. Input parameters are then converted to proper units:

1. Tota1 length of cable, SLENTH, to feet

2. Increment of length, SLINC, to feet

3. Diameter of cable, DIAM, to feet

4. Haul in speeds, PAYRAT(N), to feet/second

5. Angle of roll, ANGROL, to radians 
At this point, the program calculates those parameters independent of cable length:

1. Distance from ship centerline at the waterline to head sheave: RSHIV $=(X S H I V * X S H I V+Y S H I V * Y S H I V) * * .5$, feet

2. Angle which RSHIV makes with the horizontal: BETA = ARCTAN(YSHIV/XSHIV), radians

3. Amplitude of vertical motion head sheave undergoes from the low point of the cycle to the resting point: TOTAMP $=$ HEVAMP+RSHIV *(SIN (BETA $)-$ SIN $($ BETA-ANGROL $))$, feet

3a. Amplitude of motion TOTAMP is printed out at this point

4. Lower limit of the interval known to contain maximum dynamic tension: $\operatorname{PAR}(1)=3 . * \operatorname{PERIOD} / 4$, seconds

5. Upper limit of the interval known to contain maximum dynamic tension: $\operatorname{PAR}(\mathrm{Z})=$ PERIOD, seconds

6. Immersed weight per foot of cable: WTFOOT $=$ WT $1000 / 1000-16 . * 3.1416 *$ DIAM*DIAM, $1 \mathrm{~b} / \mathrm{ft}$

The program then starts the calculation sequence dependent on cable length and begins to do loop for the different haul in speeds. At this point, the table heladings, etc., for the haul in speed are output. Next, the do loop for the different cable lengths is begun and the following variables dependent on cable length, CABLEN, are computed:

1. Total drag coefficient

DRAGCO $=$ CDLINE $* 3.416 *$ DIAM $^{2}$ CABLEN+CDAI, feet $^{2}$

2. Virtual mass of the cable

VMCAB $=$ WT $1000 *$ CABLEN $/ 32000 .$, slugs

3. Total virtual mass

VMTOT $=$ VMCAB+VMINST, slugs

4. Immersed weight of cable

WTCAB $=$ WTFOOT $*$ CABLEN, $1 \mathrm{bs}$ 
For the non-static cases the program next calls the IMSL subroutine ZXFIB which is a minimizing iterative routine based on the Fibonacci technique. ZXFIB, in turn, calls the function subroutine TENDYN which supplies ZXFIB with the values of the function we wish to maximize, namely the dynamic tension. Since ZXFIB is a minimizing routine, the actual value sent from TENDYN is the inverse of the dynamic tension. In this way, within the specified increment length input as TOL, the time, TIMAX, at which the maximum dynamic tension occurs is returned to the main program. This value of time, TIMAX, is then used to calculate the dynamic vertical velocity, VYDYN, and acceleration, AYDYN, of the sheave.

The calculation sequence for the remainder of the program is as follows:

1. Total vertical velocity:

VYTOT $=$ VYDYN+PAYRAT $(N)$, feet $/$ second

2. Tension in the cable due to drag:

TENDRG $=$ DRAGCO *VYTOT *VYTOT, $1 \mathrm{bs}$

3. Tension in the cable due to inertia:

TENINR $=$ VMTOT $* A Y D Y N, 1 \mathrm{bs}$

4. Maximum tension in the cable due to both static and dynamic components: TENMAX = WTCAB+WTINST+TENDRG+TENINR, 1bs

The results for this cable length are then printed out and the value of TENMAX is compared with CBSTR, which is the rated breaking strength of the cable. If TENMAX is greater than CBSTR the following message is printed out:

TENSION IN CABLE EXCEEDS BREAKING STRENGTH --- CABLE BREAKS!!!

and the program goes to the next case. When TENMAX is less than CBSTR the program returns to the beginning of the cable length do loop, increments CABLEN by SLINC, and repeats the procedure until CABLEN=SLENTH when the program will go to the next case. After all the different cases have been completed the program stops.

INPUT: Al1 input to the program is from the terminal for on-line jobs, or the card reader for batch jobs. The input is described completely in the OPERATING INSTRUCTIONS below. 
OUTPUT: All output is to the terminal for on-line jobs or to the printer for batch jobs. For on-line jobs, instructions to the user are output to the terminal. Samples of output are included in the OPERATING INSTRUCTIONS below.

OPERATING INSTRUCTIONS:

I. On-1ine usage

1. To start the program respond to the !prompt from the system by entering:

PLATEN-80

This command allows output to fit on paper. The computer should respond with another !prompt, then type

S-CTDTEN

2. Program should respond:

CTDTEN -- VERSION 1.2 - AUGUST 1979

INPUT CABLE LENGTH AND CABLE INCREMENT IN METERS ?

Respond by entering these numbers. Input is free field: numbers can

1. be specified in any normal way, separated by spaces or a comma. Should

a mistake be noticed after the return key has been hit, exit the program with a Control $\mathrm{Y}$ and restart the program.

Program asks:

INPUT DRY WT./1000 FT(LB/1000FT) AND DIAMETER(INCHES) OF CABLE ?

Respond by entering these values.

INPUT DRAG COEFFICIENT AND RATED BREAKING STRENGTH(LB)OF CABLE ?

Enter these.

INPUT IMMERSED WT(LB), DRAG CONSTANT (FT*FT)\& VMASS OF INSTRUMENT ?

Continue.

INPUT X(FT) AND Y(FT) TO LOCATE SHEAVE 
Input these values.

INPUT PERIOD(SEC), HEAVE AMPLITUDE(FT),AND THE ANGLE OF ROLL(DEGREES) ?

Next .

INPUT NO.OF DIFFERENT HAUL IN SPEEDS TO BE RUN - -N=?

?

Input an integer - either $1,2,3,4$, or 5 .

INPUT N HAUL IN SPEEDS (METERS/MINUTE)

?

Input the same number of speeds, separated by a space, as you specified by $\mathrm{N}$.

INPUT TOLERANCE

?

Tolerance must be input in a F6.4 format. For most cases, input tolerance $=.01$. For sma11 amplitude cases, where HEVAMP is less

than 2 feet and ANGROL is less than 10 degrees, ZXFIB may not be able to minimize within the small increment of time specified by tolerance. In a11 cases, start with .01 then increase if program aborts to .05 then 1.

Batch: Here is a sample deck set-up for a batch run of CTDEN, with a11 data input on cards.

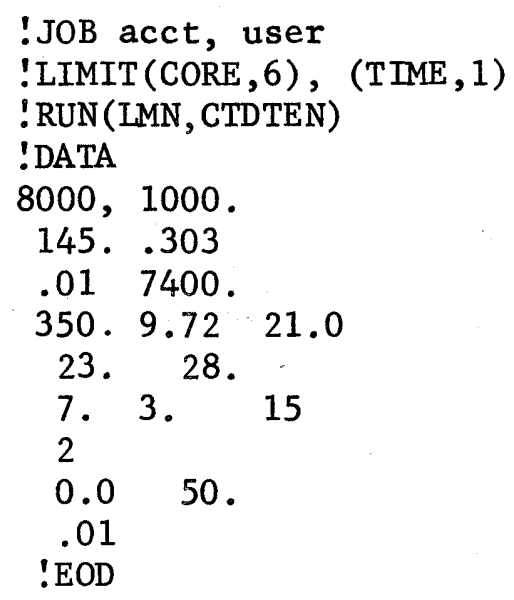


III. SAMPLE PRINTOUT

!PLATEN 80

: S CTDTEN

CTDTEN - VERSION 1.2 -- AUGUST 1979

INPUT

INPUT TOLERANCE

$? 0.01$

The program now prints out all input parameters and the amplitude of motion:

INPUT PARAMETERS

AMPLITUDE OF MOTION - 11.03

The program begins computations and prints out results for each case: RESULTS FOR CASE NUMBER 1

*STOP*

RESTRICTIONS :

l.

STORAGE REQUIREMENTS: Wi11 run in $6 \mathrm{~K}$

SUBPROGRAMS REQUIRED: AMITERM (from the account 3 library)

ZXFIB,VERTST (from the IMSL 1ibrary)

TENDYN (function subroutine with main program)

OPERATIONAL ENVIRONMENT: 
Device

Card Reader or

Termina1

Line Printer or

Termina1

TIMING: Fast

PROGRAMMER: Michael F. Cook

ORIGINATOR: Henri 0. Berteaux

DATE: $\quad$ August, 1979
Function

input

output
Specia1 Requirement

F : 105 DCB

F : 108 DCB 
APPENDIX 8

MEASUREMENT OF CTD PACKAGE TERMINAL VELOCITY 
MEASUREMENT OF CTD PACKAGE TERMINAL VELOCITY

One way to determine the velocity of a free falling instrument is to record the distance it travels as a function of time. An ingenious scheme to obtain such a record is to wind a small wire on a bicycle wheel mounted on a stand. The end of the wire is attached to the object and the object let free to fall. As the object accelerates it pulls the wire which in turn drives the whee1. The wheel rotary motion is transformed into a voltage output by means of a multiturn potentiometer driven by the wheel. This roltage is then fed into a recorder which produces a plot of distance traveled as a function of time. The slope of this curve yields the instantaneous velocity of the object. When the slope becomes constant the object has reached termina1 velocity.

At terminal velocity $V_{T}$ the forces acting on the object, neglecting the very small pull and drag of the wire, are the object immersed weight "W" and drag, both equal and opposite. The following equation then prevails:

$$
W=\frac{1}{2} \rho C_{D} \cap V_{T}^{2}
$$

from which

$$
C_{D} A=\frac{2 W}{\rho V_{T}^{2}}
$$

where $C_{D}$ is the object drag coefficient

$A$ is the object area normal to the flow $\left(f t^{2}\right)$

$\rho$ is the water mass density (slugs/ft ${ }^{3}$ ).

A measure of terminal velocity can thus yield an experimental value of the drag constant $C_{D} A$, a parameter difficult to estimate particularly when dealing with objects of complex shape.

The terminal velocity of a CTD package was measured using the scheme just described. The package, as shown in Figure 16, contained a CTD 
instrument, a water sampler rosette, and a nephelometer. Overall dimensions of the package were 48 inches diameter by 93 inches high. Its weight in air was 560 lbs and in water $3501 \mathrm{bs}$.

The measured terminal velocity of this package was found to be 6.0 $\mathrm{ft} / \mathrm{sec}$ (110 meters/minute) and the computed drag constant was $9.72 \mathrm{ft}^{2}$.

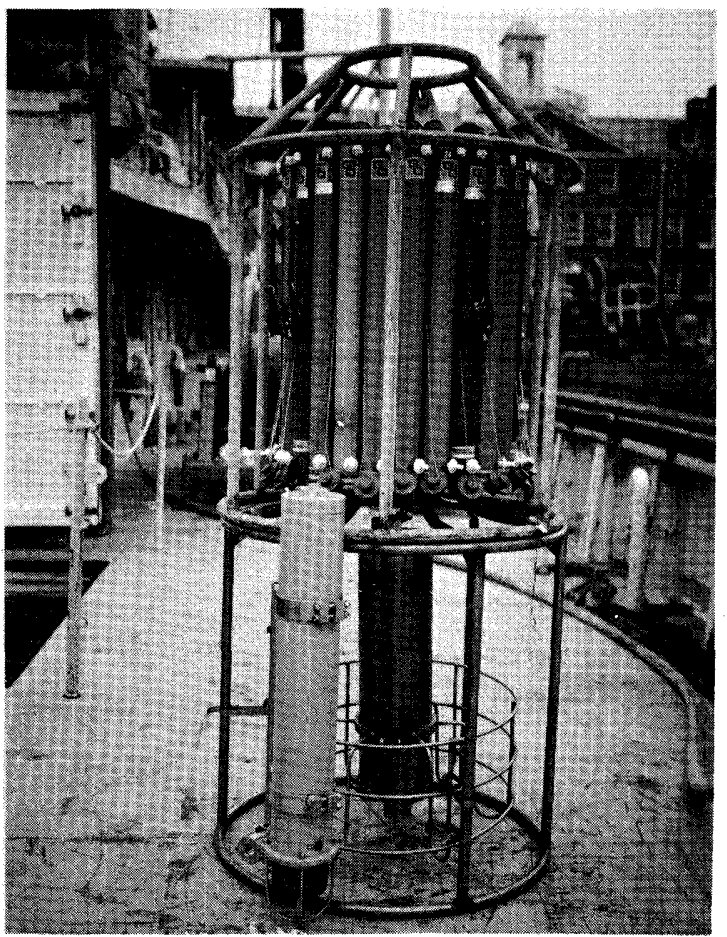

Figure 16. Typical CTD Instrument Package 
APPENDIX 9

SPOOLING E/M CABLE ON SMOOTHED SURFACE DRUMS 
Pg. 1 of 6

\section{APPENDIX 9}

SPOOLING E/M CABLE ON SMOOTHED SURFACE DRUMS

The Spooling of Armored Amergraph cable on a smooth surface winch drum requires proper handling equipment, plus proven installation techniques. After the cable is installed, the winch operator must also use correct operating methods or the best spooling effort can be lost.

Condition of Drum

The winch drum should be in good mechanical condition; the core surface should be smooth and straight with no dishing; and the flanges must be perpendicular to the drum core. Removing Cable from Shipping Reel

Normal installation requires spooling from the top of the shipping reel to the top of the winch drum. The cable bed layer can travel from left to right or right to left, but a back tension of some form should be held, as the cable is spooled on the winch drum. Proper back tension allows removal of the cable from the shipping reel without cutting into the lower layers and can best be accomplished by using a tension capstan between the shipping reel and the winch. This arrangement not only prevents cable damage on the shipping reel, but allows for the use of pre-calculated tension under controlled conditions.

\section{Proper Alignment}

For a cable to be spooled properly, the angle from the winch drum to the first fixed point should be correctly established. This is known as the fleet angle and should be no greater than $1 \frac{1}{4}^{\circ}$ at the flange. The approximate distance required to develop this angle is found by multiplying the drum width by 25 ; thus, for every foot between flanges of the drum, a distance of 25 feet is needed to the fixed point. 
Pg. 2 of 6

\section{Basic Spooling Concept}

The main concept of controlled cable spooling is to apply the first layer in a predetermined pattern that can be readily reproduced on the second and a11 subsequent layers.

During spooling, the cable should lie parallel to the flanges except for the two cross-over sections where the cable moves across the drum onehalf pitch ( $\frac{1}{2}$ cable diameter) to give a full pitch movement per drum revolution.

The area of the cross-over or "break" points covers about $10 \%$ of the circumference of the drum. This area is divided between the two cross-over sections spaced $180^{\circ}$ apart, thus creating a counter-balanced effect on the drum.

\section{Establishing Cross-over Points}

The winch drum should have an entry hole on the side of one flange where it joins with the core. This hole should be drilled just slightly larger than the cable and at an angle to allow movement of the cable along the face of the flange without a sharp bend. A clamp or other means should be used to keep the cable from pulling back through the entry hole.

The first cross-over point is developed at the entry hole. Using a carpenter's square (held at right angle with core and flange) and a chalk stock, draw a line from the center point of the entry hole across the drum core to opposite flange. This line should be carried up on both of the flanges

The second cross-over point is located $180^{\circ}$ from the first and marked in the same manner. This point can be quickly located by wrapping a length of the unarmored conductor core around the full circumference of the drum barre1. Dividing this into two equal lengths, take one length (holding one end at the first chalk mark) and wrap it wround the drum core. Then place a mark at the opposite end; it should be $180^{\circ}$ from the first cross-over point. 
Sometimes it is found helpful to add an additional chalk line parallel to each of the two cross-over lines. This line is positioned to show where "break" should finish. This line should be about 3 " from the main cross-over line when spooling a 15/32" diameter cable and proportionately less for smaller cables.

\section{Calculating First Layer on Drum}

The next step is to determine how many turns of cable will be needed for the first or bed layer to wrap around the core and fill the area between flanges. It is suggested that the cable diameter be divided into the measurement between flanges; thus, if using a .200" OD cable with 20 " between flanges, 100 turns would be required to fill the drum.

This method should work well within a half turn. If slightly more or less is required, add or remove a half turn. Judgement must be used in an effort not to disturb the bed layer any more than needed. Generally, cables will spool, or thread lay, easier if a half turn is removed than when an extra half turn is added.

After the required number of turns is determined, the cable end is inserted through the entry hole near the side of the flange where it is properly tied down and prepared for connection to the collector ring. The drum is then rotated to add three or four turns. Just enough back tension is used to hold cable in place.

Beginning Installation

Using a hammer (Blacksmith) and dul1 nosed ( $\left.3^{\prime \prime}\right)$ chise1, work the cable away from the flange (starting at the break point $180^{\circ}$ from the entry hole, continuing around to the entry hole) and insert the first length of packing material between the flange and the cable. The packing material (approximately $\frac{1}{2}$ diameter of cable) is fitted into place with the hammer and chisel as the drum rotates slowly with all turns being moved into proper 
position. (Generally, the unarmored conductor core can be used as packing materia1).

After the first length of packing has been inserted, continue to rotate the drum, adding the balance of cable required for the bed layer. Correct Back Tension

Back tension is very important from this point on. Generally, just enough tension is used on the bed layer to obtain the required number of turns. Using too much tension will cause the cable to oval and not allow the required number of turns to fit between the flanges. Normal tension on the first layer would be approximately $10-15 \%$ of the breaking strength of the cable. On a 7/32" cable, we suggest using $4001 \mathrm{bs}$ and $1,5001 \mathrm{bs}$ on a 5/16" cable. (See table for suggested tensions.)

\begin{tabular}{|c|c|c|c|c|}
\hline Cable Size & Ist Layer & 2nd Layer & 3rd Layer & Balance \\
\hline $3 / 16$ & $3001 \mathrm{bs}$ & $4501 \mathrm{bs}$ & $650 \mathrm{lbs}$ & \multirow{5}{*}{$\begin{array}{l}\text { Tension held for } \\
\frac{1}{2} \text { of the cable } \\
\text { length, then re- } \\
\text { duced by the } \\
\text { weight (1bs per } \\
M^{\prime} \text { ) of cable as } \\
\text { each } 1,000^{\prime} \text { is } \\
\text { installed. This } \\
\text { is done until a } \\
\text { minimum of } 200- \\
300 \text { lbs is reach } \\
\text { ed on } 7 / 32^{\prime \prime} \text { and } \\
\text { smaller cable } \\
\text { and } 1,000 \text { on } \\
\text { larger cable. } \\
\text { This minimum is } \\
\text { then held until } \\
\text { the entire cable } \\
\text { is installed. }\end{array}$} \\
\hline $7 / 32$ & $4001 \mathrm{bs}$ & $6001 \mathrm{bs}$ & $8501 \mathrm{bs}$ & \\
\hline $5 / 16$ & $1,5001 \mathrm{bs}$ & $2,0001 \mathrm{bs}$ & $2,8001 \mathrm{bs}$ & \\
\hline $7 / 16$ & $2,500 \mathrm{lbs}$ & $3,5001 \mathrm{bs}$ & $4,5001 \mathrm{bs}$ & \\
\hline $15 / 32$ & $2,500 \mathrm{lbs}$ & $3,5001 \mathrm{bs}$ & $4,500 \mathrm{Ibs}$ & \\
\hline
\end{tabular}




\section{Insta1ling Second and Third Layers}

Before adding the last turn to fill the drum on the first layer, the decision must be made as where the second length of packing material should be placed. If no additional turns appear to be needed, the second packing should be inserted in the $0^{\circ}$ to $180^{\circ}$ position or on the opposite (bottom) side from the first packing. If an additional half wrap is required, it should be inserted (using hammer and chisel to evenly move cable turns closer together) in the $180^{\circ}-360^{\circ}$ position or directly across (top) from the first packing.

With the drum again rotating slowly, the tension should be increased to approximately 15 to $20 \%$ of the cable's rated breaking strength to add the second layer.

After the second layer has been added, again check for proper fleet angle. This may require movement of equipment to obtain correct position. Slight adjustments, using hammer and chisel, may also be required to help develop proper cross-over points.

During application of the third layer, the tension should be increased to approximate1y $20-25 \%$ of breaking strength. At the end of the third layer, fleet angle and break points should again be checked and any slight adjustments made.

\section{Completion of Spooling/Points to Watch}

From this point on, as each layer is added, the "break" points should move back slightly. This can be checked with the chalf marks located on the side of the flanges. If the "break" line moves back too quickly, it means there are too many turns in bed layer.

Should the "break" line move forward very quickly, it means there are not enough turns in bed layer. This also causes large spaces between cable turns, which allows the cable to "crack out" or develop "low spots". 
Good spooling can be obtained if the equipment is in good condition and properly handles. Working with the known oD of the cable plus proper handling of back tension and fleet angle, will generally insure good thread lay spooling with a minimum of effort.

The foregoing information is intended only as a "standard guide" for normal hoisting conditions. It is not intended to cover every detail nor satisfy every operating condition. Many special services, such as deviated and extremely deep hole work, may require some modification of these procedures to suit the special conditions. 


\section{REFERENCES}

1. E. A. Capadonna, "Flexure Cycling Test of TRC7H4 Cable Acted on by Martin Decker Dynamometer", Preformed Line Products Company Test Report. January 1974.

2. A. G. Berian, "Design and handling factors in the reliability and life of electrical wire lines", Proceedings of Interocean 1976, Dusseldorf, West Germany.

3. Holmes, P., "Mechanics of Raising and Lowering Heavy Loads in the Deep Ocean: Cable and Payload Dynamics", U. S. Naval Civil Engineering Laboratory, Technical Report R-433. April 1977.

4. Liu, F. C., "Snap Loads in Lifting and Mooring Cable Systems Induced by Surface Wave Conditions", Naval Civil Engineering Laboratory Technical Note N-1288. September 1973.

5. Migliore, H. and Zwibe1, H., 'Dynamic treatment of cable systems which change length with time", Canadian Conference of Applied Mechanics, Vancouver, B.C. May 1978.

6. Migliore, H. and R. L. Webster, "Current Methods for Analyzing Dynamic Cable Response", The Shock and Vibration Digest, Volume II, No. 6. June 1979.

7. K. M. Ferer and R. C. Swenson, "Kevlar Cable Development Program", Naval Ocean Research and Development Activity, NORDA Report 15. January 1978.

8. M. K. Barnoski, Fundamentals of Optical Fiber Communications, Academic Press, New York, 1976.

9. H. G. Unger, Planar Optical Waveguides and Fibers, Oxford University Press, New York, 1977.

10. M. S. Sodha and A. K. Ghatak, Inhomogeneous Optical Waveguides, P1enum Press, 1977.

11. T. Ito, et a1, Transmission experiments in the 1.2-1.6 $\mu \mathrm{m}$ wavelength region using graded-index optical fibers, paper TUB1 presented as OSA meeting, March 6-10, Washington, D.C., 1979.

12. T. Mayashita et a1, An U1timate Low Loss Single Mode Fiber at $1.55 \mu \mathrm{m}$, ibidem.

13. Maurer, R. D., in Digest of Topical Meeting on Optical Fiber Transmission II, Optical Soc. Amer., 1977, Washington, D.C.

14. Kurkjian, C. R., ibidem, 1979.

15. Krohn, D. A., Cooper, A. R., Strengthening of Glass Fibers I:

Cladding, J. Am. Ceramic Soc., 52, 661-664, 1969. 
16. Mohr, R. K. et al, Strength Increase of Fibers After Aging Under Load, paper TUC4, OSA/IEEE Topical Mtg. on Fiber Optics, Washington, D. C. March 1979.

17. R. Olshansky, Distortion Losses in Cabled Optical Fibers, App. Opt. 14:1, pp 20-21. January 1975 .

18. R. F. Gleason, R. C. Monde11o, B. W. Fellows, D. A. Hadfield, "Design and Manufacture of an Experimental Lightguide Cable for Undersea Transmission Systems", paper presented at 27th Int'1 Wire Cable Symposium. November 1978.

19. University National Oceanographic Laboratory System (UNOLS), "Basic Minimum Scientific Support Capabilities for UNOLS Vessels: Supply, Operation and Maintenance", Texas A \& M University Workshop, February 1979, UNOLS Report, Woods Hole, Massachusetts.

20. University of Rhode Island, Graduate School of Oceanography,

"Report of the Committee on Winch Operations and Procedures", 1979. 


\begin{tabular}{|c|c|}
\hline REPORT DOCUMENTATION PAGE & $\begin{array}{l}\text { READ INSTRUCTIONS } \\
\text { BEFORE COMPLETING FORM }\end{array}$ \\
\hline $\begin{array}{c}\text { 1. REPORT NUMBEF } \\
\text { WHDI -79-81 }\end{array}$ & 3. RECIPIENT'S CATALOG NUMBEA \\
\hline \multirow[t]{2}{*}{$\begin{array}{l}\text { 4. TITLE (and Subittite) } \\
\text { A STUDY OF CTD CABLES AND LOWERING SYSTEMS }\end{array}$} & $\begin{array}{l}\text { 5. TYPE OF REPORT PERIOD COVEREO } \\
\text { Technical }\end{array}$ \\
\hline & 6. PERFORMING ORG. REPORT NUMDER \\
\hline $\begin{array}{l}\text { 7. AUTHOR(o) } \\
\text { H.O. Berteaux, R.G. Walden, D.A. Moller, } \\
\text { Y.C. Agrawal }\end{array}$ & $\begin{array}{l}\text { 8. CONTRACT OR GRANT NUMBER(O) } \\
\text { N00014-76-C-0197; }\end{array}$ \\
\hline $\begin{array}{l}\text { 9. PERFOAMING ORGANIZATION NAME AND ADDRESS } \\
\text { Woods Hole OCeanographic Institution } \\
\text { Woods Hole, MA 02543 }\end{array}$ & $\begin{array}{l}\text { 10. PROGRAM ELEMENT. PROJECT, TASK } \\
\text { AREA Q WORK UNIT NUMBERS } \\
\text { NR } 083-400\end{array}$ \\
\hline $\begin{array}{l}\text { 11. CONTROLLING OFFICE NAME AND ADDRESS } \\
\text { NORDA }\end{array}$ & $\begin{array}{l}\text { 12. REPORT OATE } \\
\text { December } 1979\end{array}$ \\
\hline $\begin{array}{l}\text { National Space Technology Laboratory } \\
\text { Bay St. Louts, MS } 39529\end{array}$ & $\begin{array}{l}\text { 13. NUMBER OF PAGES } \\
93\end{array}$ \\
\hline 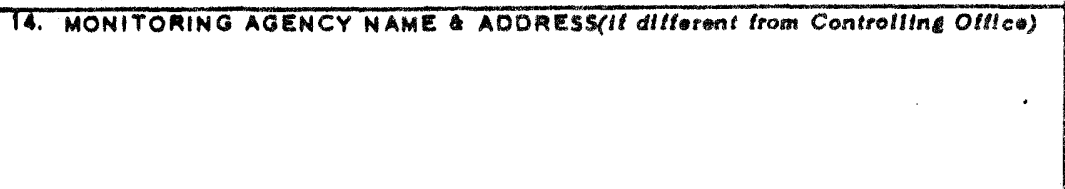 & 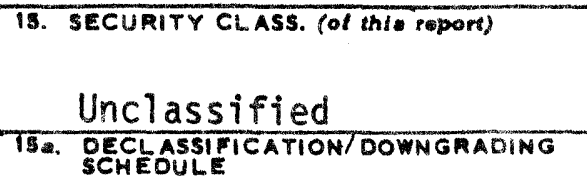 \\
\hline
\end{tabular}

16. DISTRIOUTION STATEMENT (OF thle RepOPi)

Approved for public release; distribution unlimited.

17. DISTAIBUTION STATEMENT (of the ebstewet entered in Block 20, if differeni trom Report)

18. SUPPLEMENTARY NOTES

19. KEY WOROS (Continue on pevereo olde ll neceseary and ldantlly by block number)

1. CTD Lowering Systems - Cables \& Winches

2. Electromechanical Cables - Shipboard/Oceanographic

3. Cable - Fiber Optics Oceanographic

20. ABSTRACT (Continue on revorne alde It necenery and ldentth by block nuenber)

This study first reviews both the electrical and mechanical modes and causes of fallure of electromechanical (E/M) cables used to lower deep sea sensors, such as CTD instruments, from oceanographic ships.

It then outlines measures or steps that could be taken to correct same of the deficiencies observed and improve the systems presently used. These measures include quality control, tests, operational limits, (Cont. on back) 
improved handling and maintenance, improved machinery.

The study then surveys alternative cables for lowering the sensors and convey the information from the sensors back to the ship. These alternatives include strength members other than steel (Kevlar) and signal carriers other than conventional copper conductors (fiber optics).

The final section - Conclusions - summarizes the recommendations, based on this study, for improving the reliability of present and future CTD lowering systems. 